\title{
Megakaryocytes possess a functional intrinsic apoptosis pathway that must be restrained to survive and produce platelets
}

\author{
Emma C. Josefsson, ${ }^{1,2,7}$ Chloé James, ${ }^{1}$ Katya J. Henley, ${ }^{1,2}$ \\ Marlyse A. Debrincat, ${ }^{1,2,7}$ Kelly L. Rogers, ${ }^{5,7}$ Mark R. Dowling, ${ }^{6,7}$ \\ Michael J. White, ${ }^{1,2,7}$ Elizabeth A. Kruse, ${ }^{1,2,7}$ Rachael M. Lane, ${ }^{1,2}$ \\ Sarah Ellis, ${ }^{8}$ Paquita Nurden, ${ }^{9}$ Kylie D. Mason, ${ }^{2,3,4,7}$ Lorraine A. O'Reilly, ${ }^{3,7}$ \\ Andrew W. Roberts, ${ }^{2,7}$ Donald Metcalf, ${ }^{2,7}$ David C.S. Huang, ${ }^{3,4,7}$ \\ and Benjamin T. Kile ${ }^{1,2,7}$
}

\author{
${ }^{1}$ Molecular Medicine Division, ${ }^{2}$ Cancer and Hematology Division, ${ }^{3}$ Molecular Genetics of Cancer Division, ${ }^{4}$ Chemical Biology \\ Division, ${ }^{5}$ Advanced Research Technologies, ${ }^{6}$ mmunology Division, The Walter and Eliza Hall Institute of Medical Research, \\ Parkville 3052, Australia \\ 'Department of Medical Biology, The University of Melbourne, Parkville 3010, Australia \\ ${ }^{8}$ Peter MacCallum Cancer Centre, East Melbourne 3002, Australia \\ ${ }^{9}$ Centre de Référence des Pathologies Plaquettaires, Hôpital Xavier Arnozan, 33600 Pessac, France
}

It is believed that megakaryocytes undergo a specialized form of apoptosis to shed platelets. Conversely, a range of pathophysiological insults, including chemotherapy, are thought to cause thrombocytopenia by inducing the apoptotic death of megakaryocytes and their progenitors. To resolve this paradox, we generated mice with hematopoietic- or megakaryocyte-specific deletions of the essential mediators of apoptosis, Bak and Bax. We found that platelet production was unperturbed. In stark contrast, deletion of the prosurvival protein $\mathrm{Bcl}-\mathrm{x}_{\mathrm{L}}$ resulted in megakaryocyte apoptosis and a failure of platelet shedding. This could be rescued by deletion of Bak and Bax. We examined the effect on megakaryocytes of three agents that activate the intrinsic apoptosis pathway in other cell types: etoposide, staurosporine, and the BH3 mimetic ABT-737. All three triggered mitochondrial damage, caspase activation, and cell death. Deletion of Bak and Bax rendered megakaryocytes resistant to etoposide and ABT-737. In vivo, mice with a Bak ${ }^{-/-} \mathrm{Bax}^{-/-}$hematopoietic system were protected against thrombocytopenia induced by the chemotherapeutic agent carboplatin. Thus, megakaryocytes do not activate the intrinsic pathway to generate platelets; rather, the opposite is true: they must restrain it to survive and progress safely through proplatelet formation and platelet shedding.

CORRESPONDENCE

Benjamin T. Kile:

kile@wehi.edu.au

Abbreviations used: BMC, BM cell; FasL, Fas ligand; FLC, fetal liver cell; MPV, mean platelet volume; PDW, platelet distribution width; PRP, platelet-rich plasma; STS, staurosporine.
Megakaryocytes are specialized mammalian cells responsible for the production of blood platelets. The latter are generated by an extraordinary feat of cellular remodeling (Italiano et al., 1999; Patel et al., 2005; Junt et al., 2007). Massive cytoskeletal rearrangements drive the formation of cytoplasmic extensions called proplatelets, structures along which large-scale trafficking of granules and organelles occurs. These components are packaged into nascent

C. James's present address is Centre de Référence des Pathologies Plaquettaires, Hôpital Xavier Arnozan; Université Bordeaux Segalen, Bordeaux, France; Institut National de la Santé et de la Recherche Médicale U1034, Pessac, France.

E.C. Josefsson and C. James contributed equally to this paper. platelets, which are then released from the BM into the circulation. Effectively the entire cytoplasm of a megakaryocyte is converted in this manner, each giving rise to hundreds, or potentially thousands, of platelets.

It is widely held that to produce platelets, megakaryocytes deliberately activate apoptosis (Kaluzhny and Ravid, 2004; Fadeel and Orrenius, 2005; Patel et al., 2005; Siegel, 2006; Galluzzi et al., 2008; Solary et al., 2008). A considerable
2011 Josefsson et al. This article is distributed under the terms of an Attribution-Noncommercial-Share Alike-No Mirror Sites license for the first six months after the publication date (see http://www.rupress.org/terms). After six months it is available under a Creative Commons License (AttributionNoncommercial-Share Alike 3.0 Unported license, as described at http:// creativecommons.org/licenses/by-nc-sa/3.0/ 
body of work supports this notion, most of it centered on the intrinsic (or mitochondrial) apoptosis pathway. Mice carrying mutations that impair apoptosis - by overexpression of prosurvival Bcl-2 (Ogilvy et al., 1999) or deletion of the proapoptotic Bcl-2 family member Bim (Bouillet et al., 1999) - exhibit reduced circulating platelet counts (thrombocytopenia). Overexpression of another close relative of prosurvival Bcl-2, Bcl- $\mathrm{x}_{\mathrm{L}}$, impairs proplatelet formation by cultured megakaryocytes (Kaluzhny et al., 2002). Similarly, pharmacological inhibition of caspases, the proteolytic enzymes responsible for dismantling dying cells, blocks the generation of proplatelets (De Botton et al., 2002; Clarke et al., 2003).

However, the precise requirement for apoptosis in platelet shedding has not been fully clarified. It is not understood how a megakaryocyte can undergo apoptosis and yet produce viable platelets that circulate in the bloodstream for days. Furthermore, the idea that apoptosis is required for platelet production is inconsistent with evidence that a range of insults, including chemotherapeutic agents, autoantibodies, and viruses, cause thrombocytopenia by inducing the apoptotic death of megakaryocytes and their progenitors (Ballem et al., 1987; Zucker-Franklin et al., 1989; Zauli et al., 1996; Chang et al., 2003; Houwerzijl et al., 2004; McMillan and Nugent, 2005; Zeuner et al., 2007).

Given the postulated role of the intrinsic apoptosis pathway in platelet production, we analyzed the consequences of blocking or activating apoptosis in megakaryocytes, using both genetic and pharmacological approaches. The intrinsic pathway to apoptosis is regulated by the $\mathrm{Bcl}-2$ protein family (Youle and Strasser, 2008). The key mediators of this process are Bak and Bax, which if unrestrained, trigger mitochondrial outer membrane permeabilization (MOMP), an irreversible step toward apoptotic cell death (Green and Kroemer, 2004). Combined deficiency of Bak and Bax renders multiple cell types resistant to physiological and pathological inducers of apoptosis (Lindsten et al., 2000; Cheng et al., 2001). By selectively deleting Bak and Bax within the megakaryocytic lineage, we were able to fully evaluate the consequences of blocking apoptosis on megakaryocyte biology both in vitro and in vivo. Much to our surprise, loss of Bak and Bax had no impact upon platelet production, even though platelet life span, as anticipated (Mason et al., 2007), was prolonged.

Normally, Bak and Bax are kept in check, either directly or indirectly, by the prosurvival Bcl-2 family members: Bcl-2 itself, or close relatives such as Bcl- $x_{\mathrm{L}}$ (Willis et al., 2007; Ren et al., 2010). We found that selectively inactivating prosurvival $\mathrm{Bcl}-\mathrm{x}_{\mathrm{L}}$ triggered megakaryocyte apoptosis and failure of platelet production. Three agents that activate the intrinsic apoptosis pathway in other cell types, etoposide, staurosporine (STS), and the $\mathrm{BH} 3$ mimetic $\mathrm{ABT}-737$, all triggered mitochondrial damage, caspase activation and cell death in megakaryocytes in vitro. Deletion of Bak and Bax blocked the response to etoposide and ABT-737, but not STS. In vivo, loss of Bak and Bax rescued the defects caused by deletion of $\mathrm{Bcl}-\mathrm{x}_{\mathrm{L}}$, and ameliorated the thrombocytopenia caused by the chemotherapeutic agent carboplatin. Thus, our studies overturn the notion that classical mitochondrial apoptosis is essential for platelet production. Instead, megakaryocytes must restrain apoptosis to survive and progress safely through proplatelet formation and platelet shedding. This striking finding has important implications for our understanding of human diseases where the apoptotic death of megakaryocytes has been implicated.

\section{RESULTS}

\section{Platelet number and life span are increased in the absence} of Bak and Bax

To determine the role of the intrinsic apoptosis pathway in platelet production, we generated mice with a constitutive deletion of Bak and a megakaryocyte-specific deletion of Bax. $B a k^{-/-}$animals were crossed with mice harboring a floxed allele of Bax (Bax ${ }^{\text {fl}}$; Takeuchi et al., 2005) and a Pf4-Cre transgene from which Cre recombinase is expressed under the control of the Platelet factor 4 promoter (Tiedt et al., 2007). The latter mediates efficient deletion of floxed alleles from the earliest stages of megakaryocytic differentiation (Hitchcock et al., 2008; Pleines et al., 2010; Tiedt et al., 2007). At weaning, $B a k^{-/-} B a x^{P f 4 \Delta / P f 4 \Delta}$ mice were present in the expected Mendelian ratios and were outwardly healthy and fertile. Western blot analysis of platelet and megakaryocyte lysates confirmed that Bak and Bax were efficiently deleted from the lineage (Fig. 1 a).

Consistent with the initial study (Mason et al., 2007), we found that peripheral blood platelet counts in $\mathrm{Bak} \mathrm{k}^{-1-}$ mice were significantly increased relative to wild-type counterparts (Fig. 1 b). Surprisingly, with the additional loss of Bax, platelet numbers remained elevated. Given the role these two proteins play in the regulation of platelet life span, we examined the kinetics of platelet clearance in vivo. Deletion of Bax had a minor effect, with a modest but statistically significant extension of platelet survival apparent (Fig. 1 c). In contrast, and as previously documented (Mason et al., 2007), platelet life span in $B a k^{-1-}$ mice was almost doubled. This was also true of $B a k^{-1-} B a x^{+/ P f 4 \Delta}$, and $B a k^{-/-} B a x^{P f 4 \Delta / P f 4 \Delta}$ animals; in fact, platelet survival curves in $B a k^{-/-}, B a k^{-/-}$ $B a x^{+/ P f 4 \Delta}$, and $B a k^{-/-} B a x^{P f 4 \Delta / P f 4 \Delta}$ were indistinguishable. Transfusion of biotinylated platelets into wild-type recipients established that life span in all cases was independent of host genotype, i.e., cell intrinsic (Fig. S1 d). These data confirmed that at steady state, Bak is the critical factor limiting platelet life span. Concomitant loss of Bax does not further extend circulatory survival time. The results also suggested that platelet production does not require the intrinsic apoptosis pathway.

\section{Megakaryopoiesis is normal in the absence of Bak and Bax} Given the platelet data, we examined the megakaryocyte compartment in detail. Megakaryocyte numbers in the BM, as determined by histological (Fig. 1 d) and flow cytometric analyses (unpublished data), were comparable across all genotypes. Megakaryocyte ploidy (Fig. 1 e), and serum thrombopoietin (TPO) levels (Fig. 1 f) were unchanged in 
$B a k^{-/-} B a x^{P f 4 \Delta / P f 4 \Delta}$ mice. Semisolid agar cultures of BM cells (BMCs) and splenocytes demonstrated that committed myeloid $\left(\mathrm{Bak}^{+/+} \mathrm{Bax}^{+/+}, 87.5 \pm 15.2 ; \mathrm{Bak}^{-/-} \mathrm{Bax}{ }^{P f 4 \Delta / P f 4 \Delta}, 70.3 \pm\right.$ 7.3) and megakaryocyte progenitor numbers $\left(\mathrm{Bak}^{+/+} \mathrm{Bax}+/+\right.$ $\left.21.3 \pm 7.1, \mathrm{Bak}^{-1-} B a x^{P f 4 \Delta / P f 4 \Delta} 16.3 \pm 0.5\right)$ were normal. Next, we derived mature megakaryocytes from the BM of adult $B a k^{-1-} B a x^{P f 4 \Delta / P f 4 \Delta}$ mice and assessed their ability to form proplatelets. To circumvent any potential issues relating to the timing of Pf4-Cre-mediated excision of Bax, megakaryocytes were also derived from fetal liver cells (FLC) harvested from constitutive $B a k^{-1-} B a x^{-/-}$knockout animals (Fig. 2 a). No decrease in the rate of proplatelet formation was observed in either case (Fig. 2 a and not depicted). Interestingly, proplatelet-bearing Bak- and Bax-deficient megakaryocytes a
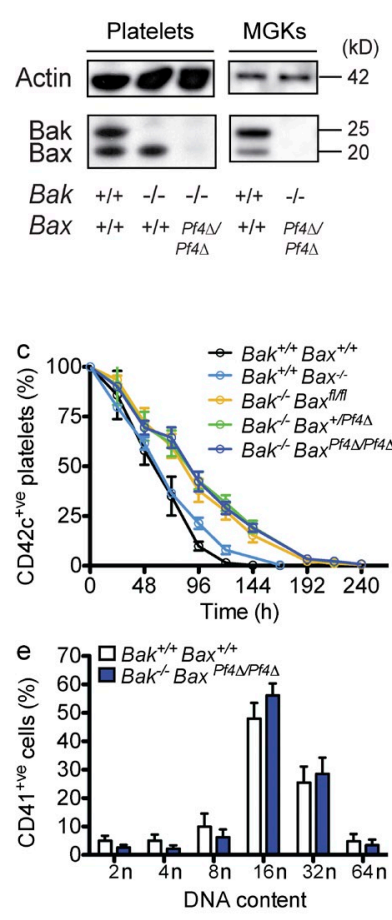

b
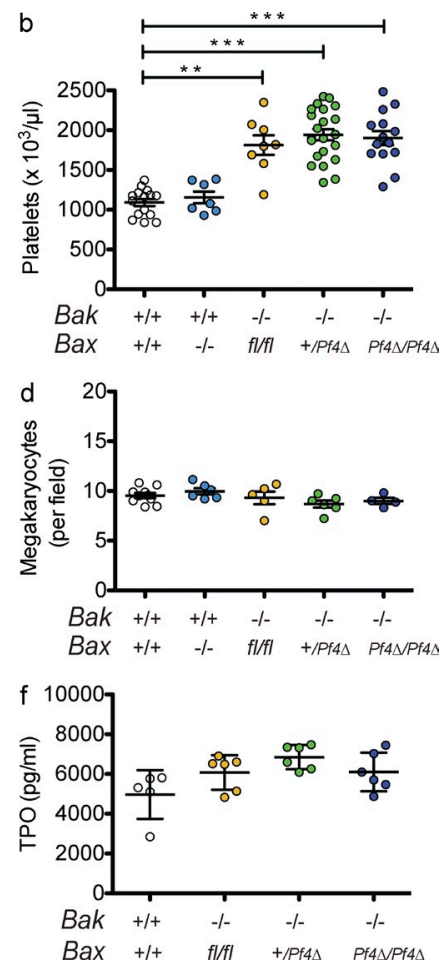

Figure 1. Thrombocytosis in the absence of Bak and Bax. (a) Western blot of $\mathrm{Bak}^{-1-} \mathrm{Bax} \mathrm{x}^{\mathrm{Pf} 4 \Delta / \mathrm{Pf} 4 \Delta}$ cell lysates demonstrating efficient deletion of Bak and Bax in platelets, and cultured megakaryocytes (MGKs) derived from murine BM. Actin served as a control for protein loading. (b) Platelet counts in $\mathrm{Bak}^{-/-} \mathrm{Bax} \mathrm{x}^{\mathrm{flffl}}, \mathrm{Bak}^{-/-} \mathrm{Bax}{ }^{\mathrm{Pf} 4 / \mathrm{Pf} 4 \Delta}, \mathrm{Bak}^{+/+} \mathrm{Bax}^{-/-}$, and control mice at 7 wk of age. Data represent mean \pm SEM. Each symbol represents an individual mouse. (c) Platelet survival curves in $\mathrm{Bak}^{-/-} \mathrm{Bax} \mathrm{ff}^{\mathrm{ffl}}, \mathrm{Bak}^{-/-}$ $B a x^{P f 4 \Delta / P f 4 \Delta}$, and $\mathrm{Bak}^{+/+} \mathrm{Bax}{ }^{-/-}$mice. Platelets were labeled via intravenous injection of a DyLight 488-conjugated anti-GPIb $\beta$ (CD42c) antibody. Data represent mean \pm SD. $n=4-6$ mice per group. (d) Morphologically recognizable MGKs in H\&E-stained sections of BM from Bak ${ }^{-1-} \mathrm{Bax}^{\mathrm{fl} / \mathrm{fl}}, \mathrm{Bak}^{-/-}$ Bax ${ }^{P f 4 \Delta / P f 4 \Delta}, B a k^{+/+} \mathrm{Bax}^{-/-}$, and control mice. Each symbol represents the mean number per field of view (200x) from 8-10 fields per individual mouse. Data represent overall mean \pm SEM. (e) MGK ploidy distribution profiles in adult conditional knockout mice. Data represent mean \pm SD. $n=8$ mice per genotype. $(\mathrm{f})$ Serum thrombopoietin levels in adult conditional knockout mice. Each symbol represents an individual mouse. Data represent mean $\pm \mathrm{SD}$. ${ }^{* *}, \mathrm{P}<0.005 ;{ }^{* * *}, \mathrm{P}<0.0001$. exhibited increased survival, persisting with proplatelets intact for several days longer than wild-type counterparts (Fig. 2, a and b).

\section{Bak- and Bax-mediated apoptosis is not required for platelet production}

Collectively, our data indicated that there is no requirement for Bak- and Bax-mediated apoptosis in the production of platelets by megakaryocytes. To rule out the possibility that this is true only at steady state, we tested the ability of $\mathrm{Bak^{-/- }}$ $B a x^{P f 4 \Delta / P f 4 \Delta}$ mice to recover from acute thrombocytopenia induced by antiplatelet serum (APS). $24 \mathrm{~h}$ after a single dose of APS, platelet counts had fallen to almost undetectable levels (Fig. 2 c). Subsequently, each genotypic class mounted a robust recovery of similar kinetics, with platelet counts exceeding baseline by $6 \mathrm{~d}$ after APS (Fig. 2 c). Interestingly, visual inspection of BM sections taken from mice during the recovery phase revealed an abundance of naked megakaryocyte nuclei (Fig. 2, d and e). This phenomenon was significantly increased in $B a k^{-1-} B a x^{P f 4 \Delta / P f 4 \Delta}$ mice relative to wild-type or $B a k^{-1-} B a x^{f / f l}$ counterparts. Although less pronounced, the difference was also observed at steady state.

Given the surprising nature of our results, we elected to confirm them by generating chimeric animals in which the hematopoietic system was reconstituted with constitutive knockout Bak $\mathrm{B}^{-/-} \mathrm{Bax^{-/- }}$ FLC (Fig. S1). These animals develop a complex disease characterized by an accumulation of lymphocytes in the peripheral blood, BM, and spleen (Rathmell et al., 2002; Fig. S1 e). In our hands, $B a k^{-1-} B a x^{-1-}$ reconstituted mice developed splenomegaly, with spleens weighing 2.5 times more than wild type at $8 \mathrm{wk}$ after transplant (Fig. S1 f). Therefore, we splenectomized a group of wild-type C57BL/6 CD45.1 recipients, and 4 wk later transplanted them with FLC. 8 wk after reconstitution, platelet counts and platelet life span in mice that had received $B a k^{-1-} B a x^{-/-}$FLC were the same as those seen in $\mathrm{Bak}^{-/-}$and $\mathrm{Bak}^{-/-} \mathrm{Bax^{+/- }}$ animals (Fig. $2 \mathrm{f}$ and Fig. S1, b and c). The response to APS-induced thrombocytopenia was normal (Fig. 2 f). These data demonstrate that at both steady state and under conditions of thrombopoietic stress, the intrinsic mitochondrial apoptosis pathway is dispensable for platelet production.

\section{$\mathrm{Bcl}-\mathrm{x}_{\mathrm{L}}$ is required for platelet survival}

Despite the fact that they express Bak and Bax, and a range of other apoptotic regulators (Krajewski et al., 1994; Sanz et al., 2001; Fig. S2 i), our results raised the question of whether megakaryocytes possess a functional intrinsic apoptosis pathway at all. If megakaryocytes are susceptible to activation of the intrinsic pathway to apoptosis, then one would expect that one or more members of the Bcl-2 family of prosurvival proteins must keep Bak and Bax in check to maintain cellular integrity. Given the known role of one such prosurvival, $\mathrm{Bcl}-\mathrm{x}_{\mathrm{L}}$, in regulating platelet life span (Mason et al., 2007), and given its documented expression in megakaryocytes (Terui et al., 1998; Sanz et al., 2001; Kozuma et al., 2007), we generated a megakaryocyte-specific deletion of $\mathrm{Bcl}-x$. Mice harboring a 

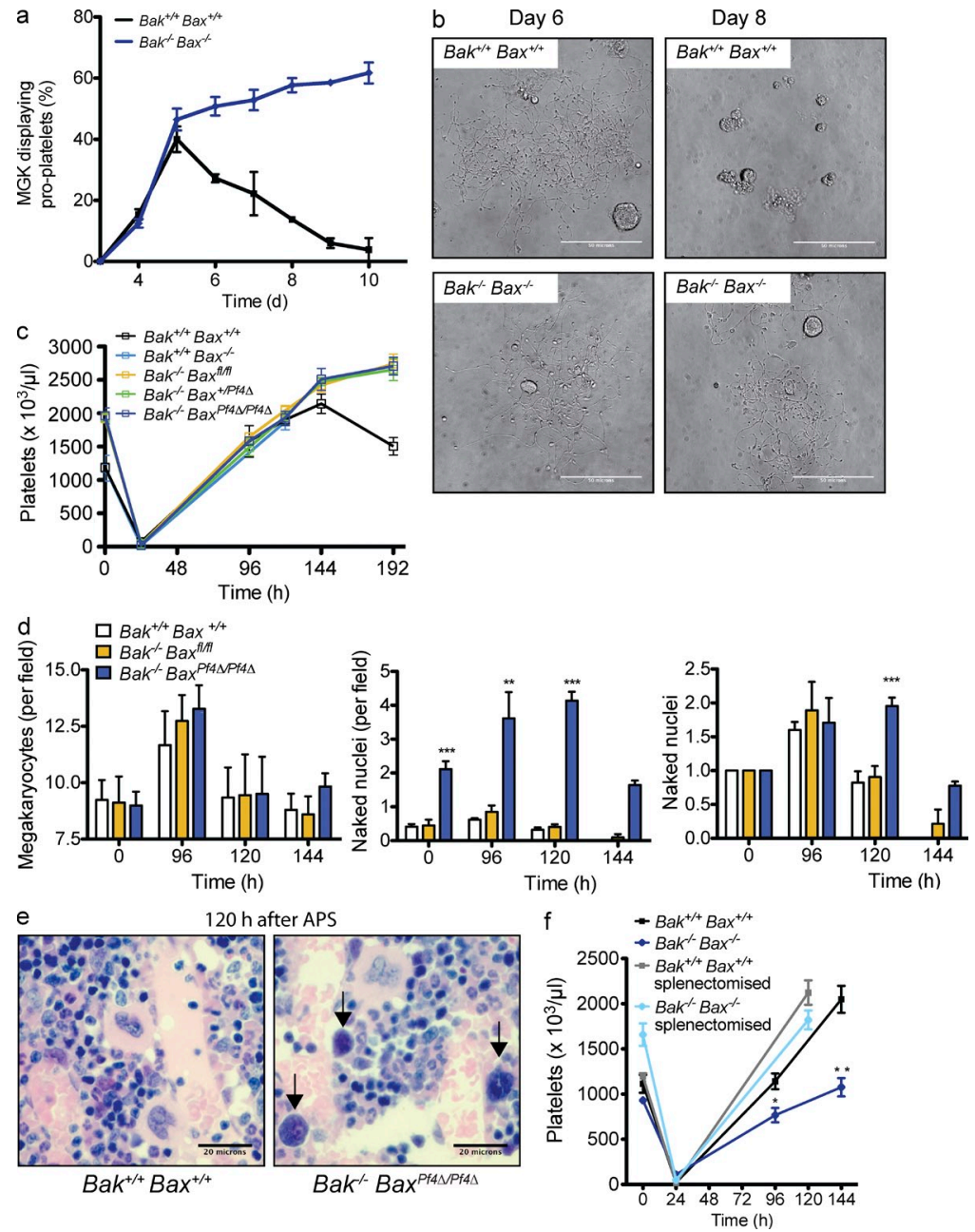

Figure 2. Bak and Bax are dispensable for platelet production. (a) Proplatelet formation by large, mature fetal liverderived MGKs in culture. Data represent mean \pm SEM. MGKs were pooled from two animals per genotype. $n=2$ technical replicates. Representative of three independent experiments. (b) Representative images of wild-type and $\mathrm{Bak}^{-/-} \mathrm{Bax}{ }^{-/-}$MGKs on day 6 and 8 of culture. On day 8 , wild-type cultures contained mostly cell debris; in contrast, $\mathrm{Bak}^{-/-} \mathrm{Bax}^{-/-}$wells contained elaborate proplatelet formations. Bars, $50 \mu \mathrm{m}$. (c) Platelet counts in response to anti-platelet serum (APS)-induced thrombocytopenia in mice lacking Bak and Bax. Data represent mean \pm SEM. $n=8-11$ mice at $120 \mathrm{~h}$ (except $\mathrm{Bak}^{+/+} \mathrm{Bax}^{-/-}, n=3$ ); $n=5-6$ at $144 \mathrm{~h}$; and $n=3-6$ at $192 \mathrm{~h}$ per genotype, per time point. ( $d$, left) Morphologically recognizable MGKs before and after APS in H\&E-stained sections of BM from mice lacking Bak and Bax. Mean number per field of view (200x) from 10 fields per individual mouse. Data represent overall mean \pm SD. $n=4-14$ untreated mice per group; $n=5-6$ at $96 \mathrm{~h} ; n=12-15$ at $120 \mathrm{~h}$; and $n=3$ at $144 \mathrm{~h}$. (middle and right) Naked MGK nuclei in H\&E-stained sections of BM from mice lacking Bak and Bax, at steady state, and in response to APS-induced thrombocytopenia (taken 96, 120, and $144 \mathrm{~h}$ after injection). (d, middle) Data represent mean number per field of view (200x) from 6 fields per individual mouse \pm SEM. $n=4-15$ untreated mice per group; $n=5-6$ at $96 h ; n=12-17$ mice per group at $120 h ;$ and $n=3$ at $144 \mathrm{~h}$. (d, right) Fold change in naked nuclei. Number of nuclei post-APS divided by mean number in corresponding untreated group ( $\mathrm{O} \mathrm{h}$ ). (e) Representative images of H\&E-stained sections of BM from wild-type and $B a k^{-/-} B a x^{P f 4 \Delta / P f 4 \Delta}$ mice, $120 \mathrm{~h}$ after injection of APS. Arrows indicate naked nuclei. Bars, $20 \mu \mathrm{m}$. (f) Platelet counts in response to APS-induced thrombocytopenia. Lethally irradiated mice were reconstituted with FLCS lacking Bak and Bax and injected with APS 8 wk after transplantation. A group of recipients was splenectomized 3-4 wk before reconstitution. Data represent mean \pm SEM. $n=7-10$ mice per group at $120 \mathrm{~h} ; n=3-5$ mice per group at 96 and $144 \mathrm{~h}$. ${ }^{*}, P<0.05 ;{ }^{* *}, P<0.005 ; * * *, P<0.0001$. floxed allele (Rucker et al., 2000) were crossed with the transgenic Pf4-Cre strain to produce $B c l-x^{P f 4 \Delta / P f 4 \Delta}$ animals. The latter were present at weaning at $\sim 80 \%$ expected numbers and appeared outwardly healthy. They were profoundly thrombocytopenic, with platelet counts of $\sim 2 \%$ those observed in $B c l-x^{f / / f l}$ mice (Fig. 3 a and Fig. S2 a). Mature cells of other hematopoietic lineages were unaffected (Table I).

$B c l-x^{P f 4 \Delta / P f 4 \Delta}$ platelets were highly abnormal: mean platelet volume (MPV) was doubled and platelet distribution width (PDW) was significantly elevated relative to $B c l-x^{f / f l}$ in peripheral whole blood (Table I). There was also an abundance of microparticles in platelet-rich plasma (PRP) as determined by flow cytometric forward and side scatter profiling, and increased phosphatidylserine (PS) exposure (Fig. 3 b and Fig. S2 b). Only 20-30\% of the cells present in PRP expressed the platelet-specific receptors CD41, GPIX, GPIb $\alpha$, or GPVI, compared with $>95 \%$ in $\mathrm{Bcl}-x^{f l / f l}$ (Fig. S2 b). To investigate circulating platelet life span, we intravenously injected mice with a fluorescently labeled platelet-specific anti-GPIb $\beta$ antibody derivative. $15 \mathrm{~min}$ after treatment, $\sim 95 \%$ of platelets were labeled in wild-type mice, but only $20 \%$ in $B c l-x^{P f 4 \Delta / P f 4 \Delta}$ littermates. The life span of the vast majority of labeled platelets was dramatically reduced to $\sim 5 \mathrm{~h}$, versus $5 \mathrm{~d}$ for wild-type and $B c l-x^{f / f l}$ littermates (Fig. 3 c). A very small number of platelets survived in the circulation up to $24 \mathrm{~h}$ after labeling (Fig. S2, c and d), potentially the product of megakaryocytes in which $B c l-x$ had not been completely excised by the Cre enzyme. Collectively, the data confirm that $\mathrm{Bcl}-\mathrm{x}_{\mathrm{L}}$ is absolutely required for platelet survival in vivo.

\section{$\mathrm{Bcl}-\mathrm{x}_{\mathrm{L}}$ is required for normal platelet shedding}

The abnormal morphology and cell surface phenotype of $B c l-x^{P f 4 \Delta / P f 4 \Delta}$ platelets suggested that platelet production had been perturbed by the loss of the $\mathrm{Bcl}-\mathrm{x}_{\mathrm{L}}$ in megakaryocytes. Mathematical modeling of production rates further supported the notion that the reduction in platelet life span could not explain the severity of thrombocytopenia (Fig. 3 d). Relative to $B c l-x^{f l f l}$ littermates, megakaryocyte numbers were significantly increased in both the BM and spleen of Bcl- $x^{P f 4 \Delta / P f 4 \Delta}$ mice (Fig. 3 e, Fig. S2 e, and not depicted). Megakaryocyte ploidy was skewed toward 32N (Fig. 3 f). Megakaryocyte progenitor numbers were somewhat increased in $B c l-x^{P f 4 \Delta / P f 4 \Delta}$ mice (Fig. 3 g), and serum TPO levels were significantly reduced (Fig. 3 h). Collectively, these data were reminiscent of 


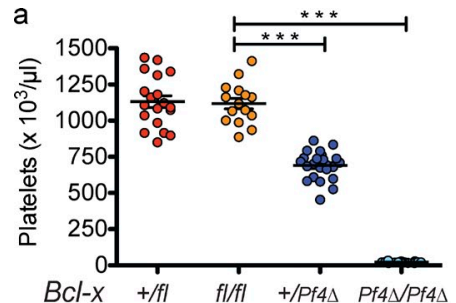

b Flow cytometric profile of CD41 ${ }^{\text {+ve }}$ cells
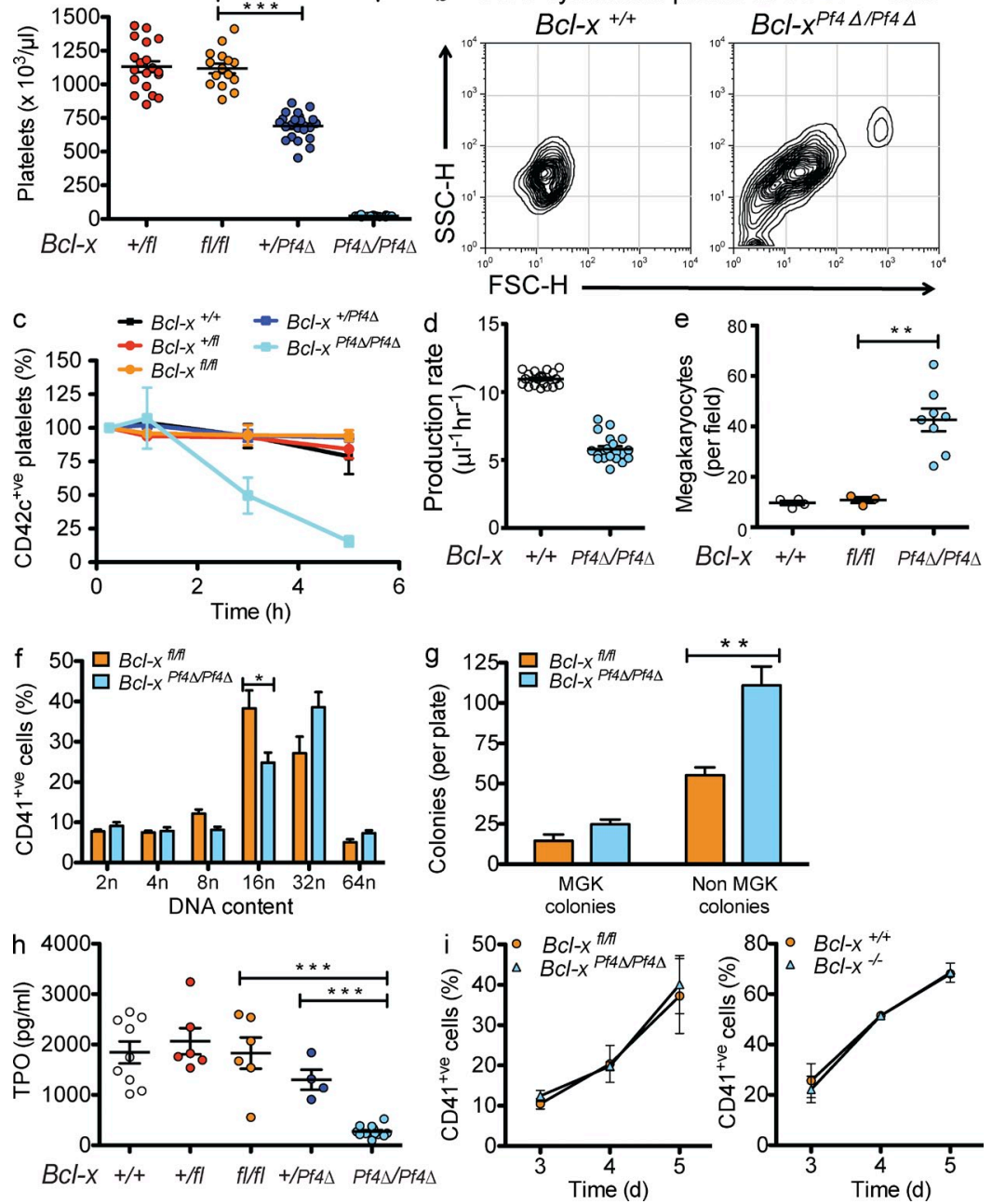

Figure 3. $\mathrm{Bcl}-\mathrm{x}_{\mathrm{L}}$ is essential for platelet survival. (a) Platelet counts at 7 wk of age in mice with a Pf4-Cre-mediated deletion of BCl-x. Each symbol represents an individual mouse. Data represent mean \pm SEM. $n=15-23$ mice per genotype. (b) Representative flow cytometric forward and side scatter profiles of CD41+ve platelets in PRP derived from wild-type and $B C l-x^{P f 4 \Delta / P f 4 \Delta}$ mice. (c) In vivo survival of CD42 $c^{+v e}$ platelets in $B C l-x^{p f 4 \Delta / P f 4 \Delta}$ mice. Platelets were labeled via intravenous injection of a DyLight 488-conjugated anti-GPIb $\beta$ (CD42c) antibody. Blood samples were collected $0.25,1,3$, and $5 \mathrm{~h}$ after labeling. Data represent mean \pm SEM. $n=8$ mice for $B c l-x^{p f 4 \Delta / P f 4 \Delta} ; n=4$ for wild type; $n=3$ for $B c l-x^{f / / f l}$; $n=$ and 2 for $B c /-x^{+/ f l}, B c l-x^{+/ P f 4 \Delta}$. P $<0.0001$ at $5 \mathrm{~h}$.

(d) Calculated platelet production rates in wild-type and $B C l-x^{P f 4 \Delta / P f 4 \Delta}$ mice as described in Materials and methods. $P<0.0001$, two-tailed unpaired Student's $t$ test. (e) Morphologically recognizable MGKs in H\&E-stained sections of BM from $B C l-x^{P f 4 \Delta / P f 4 \Delta}$ mice. Each symbol represents mean number per field of view $(200 x)$ from five fields per mouse. Data represent overall mean \pm SEM. (f) Ploidy distribution profile of $\mathrm{CD} 41^{\text {+ve }} \mathrm{BMCs}$. Data represent mean \pm SEM. $n=6$ mice per genotype. (g) Hematopoietic progenitor cell numbers in adult mice. 25,000 BMCs were cultured with stem cell factor, IL-3, and erythropoietin in semisolid agar for $7 \mathrm{~d}$. Non-MGK colonies represent the total of blast, granulocyte, mixed granulocyte/macrophage, macrophage, and eosinophil colonies. Data represent mean \pm SEM. $n=7-11$ mice per genotype. ${ }^{*}, P=0.0021$. (h) Serum TPO levels. Each symbol represents an individual mouse. Data represent mean \pm SEM. ${ }^{* * *}, P<0.0001$. (i) MGK differentiation from mouse FLC. E12.5 BCl- $x^{+/+}$ and $B \mathrm{Cl}-\mathrm{x}^{-/-}$, and $\mathrm{E} 13.5 \mathrm{BCl}-x^{\mathrm{fl} / \mathrm{fl}}$, and $\mathrm{BCl}-x^{\mathrm{Pf} 4 \Delta / \mathrm{Pf} 4 \Delta}$ fetal livers were cultured in TPO for $3-5 d$ and the development of $C D 41^{\text {tve }}$ cells measured by flow cytometry. Data represent mean \pm SD. $n=3-5$ biological replicates (except day $3, n=2$ ). ${ }^{* *}, \mathrm{P}<0.005 ;{ }^{* * *}, \mathrm{P}<0.0001$. those from mice lacking the transcription factor NF-E2, which although able to generate mature megakaryocytes, suffer a profound defect in platelet shedding and severe thrombocytopenia (Shivdasani et al., 1995; Lecine et al., 1998; Levin et al., 1999).

To elucidate the consequences of $B c l-x$ deletion on megakaryocyte development, we cultured $B c l-x^{f / f l}$ and $B c l-x^{P f 4 \Delta / P f 4 \Delta}$ FLC in serum-free media with TPO. To control for any variability in the deletion of the floxed allele of $B c l-x$, FLC from mice homozygous for a constitutive knockout allele, denoted $B c l-x^{-/-}$ (Motoyama et al., 1995), were cultured in parallel. Bcl- $x^{+/+}$, $B c l-x^{f l / f l}, B c l-x^{P f 4 \Delta / P f 4 \Delta}$, and $B c l-x^{-/-}$FLC cultures produced similar numbers of megakaryocytes (Fig. 3 i). This agreed with our in vivo data, confirming that $\mathrm{Bcl}-\mathrm{x}_{\mathrm{L}}$ is not required for the development and growth of megakaryocytes. We next assessed the ability of mature megakaryocytes to generate proplatelets. In striking contrast to gradient-purified $B c l-x^{+/+}$and $B c l-x^{f / / f l}$ megakaryocytes, $B c l-x^{-/-}$and $B c l-x^{P f 4 \Delta / P f 4 \Delta}$ cells exhibited an almost total failure of proplatelet formation (Fig. 4, a and b). This was accompanied by a rapid loss of viability.

To investigate these phenomena more closely, time-lapse video microscopy of mature megakaryocytes in culture was performed (Fig. $4 \mathrm{c}$ and Videos 1 and 2). Bcl- $x^{f / f l}$ megakaryocytes sent out long extensions and formed elaborate proplatelets. In contrast, $B c l-x^{P f 4 \Delta / P f 4 \Delta}$ megakaryocytes generated extensions, but they were significantly fewer, much shorter, and less detailed. $B c l-x^{P f 4 \Delta / P f 4 \Delta}$ megakaryocytes died soon after they had formed these short extensions. To visualize phosphatidylserine exposure, Alexa Fluor 488-conjugated Annexin $\mathrm{V}$ was included in the media (Fig. $4 \mathrm{~d}$ andVideos 3 and 4). Minimal PS was observed on $\mathrm{Bcl}-\mathrm{x}^{+/+}$megakaryocytes as they proceeded through proplatelet formation. However, several hours after the process appeared to be complete, proplatelet-bearing megakaryocytes were seen to collapse in on themselves and stain intensely positive for Annexin. Bcl- $x^{P f 4 \Delta / P f 4 \Delta}$ megakaryocytes on the other hand, did not form proplatelets, and although they were not Annexin ${ }^{+}$at the beginning of culture, they exposed increasing levels of PS as they subsequently died.

Collectively, our data suggested that megakaryocytes become dependent on $\mathrm{Bcl}-\mathrm{x}_{\mathrm{L}}$ just as they reach the point of proplatelet formation and platelet shedding. In the absence of $\mathrm{Bcl}-\mathrm{x}_{\mathrm{L}}$, mature megakaryocytes are unable to undergo normal shedding and die an apoptotic death. We looked for evidence of this process in vivo via transmission electron microscopy of 
Table I. Blood counts in mice lacking $\mathrm{BCl}-\mathrm{x}_{\mathrm{L}}$ in the megakaryocyte lineage

\begin{tabular}{|c|c|c|c|c|}
\hline & $B c l-x^{f l / f l}$ & $B c /-x^{+/ f l}$ & $B c l-x+/ P f 4 \Delta$ & $B c l-X^{P f 4 \Delta / P f 4 \Delta}$ \\
\hline & $n=12$ & $n=16$ & $n=20$ & $n=20$ \\
\hline Platelets $\left(\times 10^{6} / \mathrm{ml}\right)$ & $1,139 \pm 150$ & $1,163 \pm 170$ & $697 \pm 100^{b}$ & $22 \pm 4^{b}$ \\
\hline aPlatelets $\left(\times 10^{6} / \mathrm{ml}\right)$ & $939 \pm 92$ & & & $52 \pm 28^{b}$ \\
\hline MPV (femtoliters) & $7.7 \pm 0.6$ & $7.1 \pm 0.9$ & $7.3 \pm 0.8$ & $14.0 \pm 2.5^{b}$ \\
\hline PDW (\%) & $53.2 \pm 4.2$ & $51.2 \pm 5.6$ & $52.3 \pm 7.1$ & $78.9 \pm 20.9^{b}$ \\
\hline Erythrocytes $\left(\times 10^{9} / \mathrm{ml}\right)$ & $10.7 \pm 0.4$ & $10.7 \pm 0.5$ & $10.7 \pm 0.5$ & $10.1 \pm 0.6$ \\
\hline Hematocrit (\%) & $50.8 \pm 1.7$ & $51.1 \pm 2.2$ & $51.4 \pm 2.3$ & $49.1 \pm 2.2$ \\
\hline Leukocytes (×106/ml) & $10.5 \pm 1.7$ & $9.4 \pm 2.0$ & $10.2 \pm 2.4$ & $9.1 \pm 1.8$ \\
\hline Neutrophils (×106/ml) & $0.8 \pm 0.2$ & $0.8 \pm 0.1$ & $0.9 \pm 0.2$ & $0.8 \pm 0.2$ \\
\hline Lymphocytes $\left(\times 10^{6} / \mathrm{ml}\right)$ & $9.1 \pm 1.5$ & $8.0 \pm 1.8$ & $8.8 \pm 2.3$ & $7.6 \pm 1.6$ \\
\hline Monocytes (×106/ml) & $0.2 \pm 0.1$ & $0.2 \pm 0.0$ & $0.2 \pm 0.1$ & $0.3 \pm 0.1$ \\
\hline Eosinophils $\left(\times 10^{6} / \mathrm{ml}\right)$ & $0.2 \pm 0.1$ & $0.2 \pm 0.1$ & $0.2 \pm 0.1$ & $0.2 \pm 0.1$ \\
\hline
\end{tabular}

Peripheral blood cell counts from mice at 7 wk of age. MPV, mean platelet volume; PDW, platelet distribution width. Data represent mean \pm SD.

aplatelet counts in whole blood determined by flow cytometry with Sphero blank calibration particles (3.5-4.0 $\mu \mathrm{m})$, gating on CD41+ve and TER-119-ve cells. $n=3$ mice per genotype. Unpaired Student's $t$ test with two-tailed $p$-values.

${ }^{b} \mathrm{P}<0.001$, with respect to control mice $B c l-x^{f / f f}$ or $B C l-x^{+/ f l}, 1$ way ANOVA with Bonferroni's multiple comparison correction.

$B c l-x^{f / f l}$ and $B c l-x^{P f 4 \Delta / P f 4 \Delta}$ BM sections. As expected, many megakaryocytes displaying normal ultrastructure were observed in the knockout (Fig. 5 a, bottom left). However, strikingly abnormal cells, projecting large vacuolated fragments of cytoplasm into the sinusoidal spaces were also evident (Fig. 5 a, bottom middle; and Fig. S3). Discrete fragments that had been
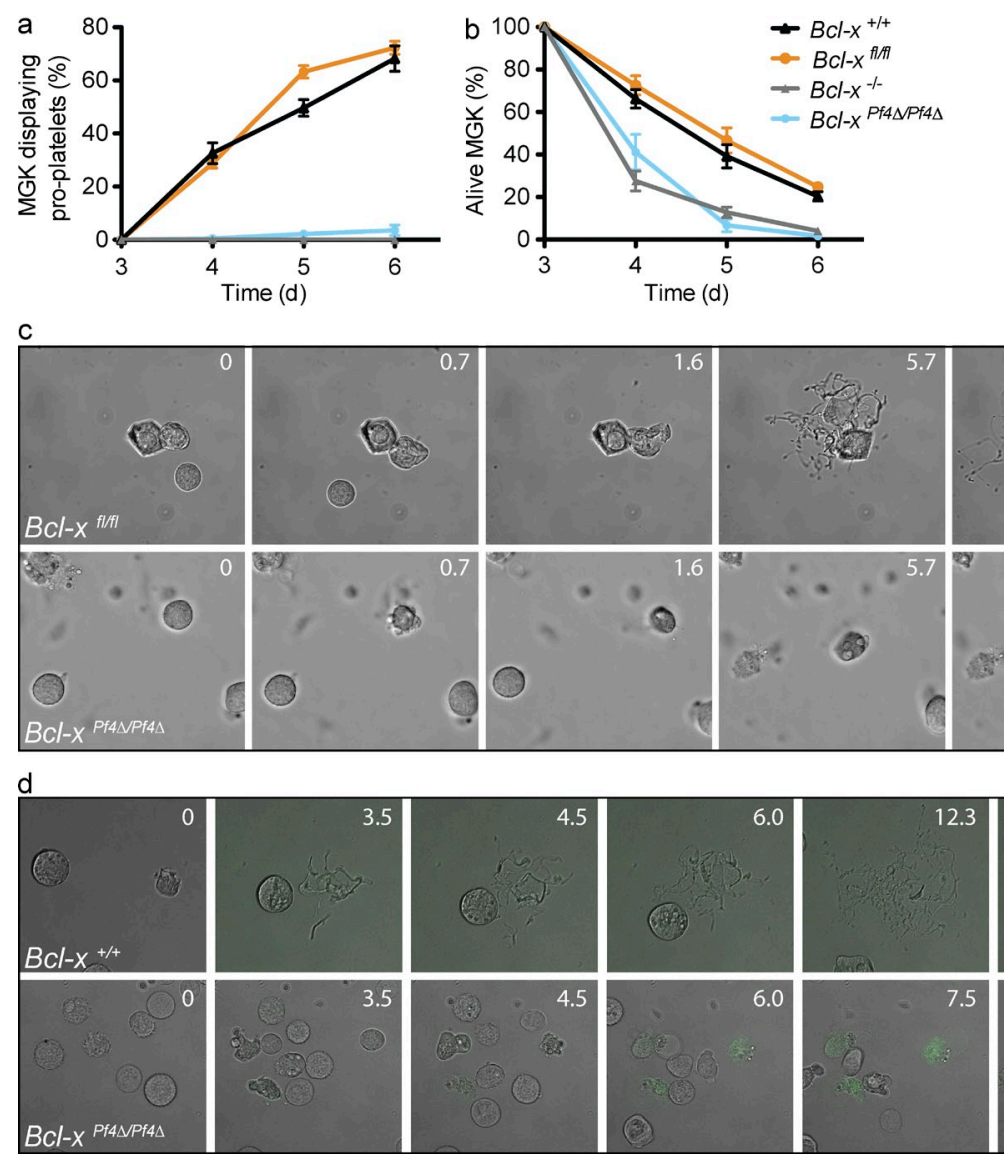
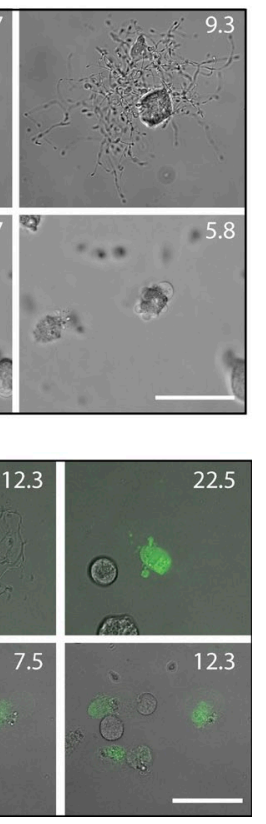

shed were seen in the circulation; they appeared to be highly vacuolated and morphologically abnormal (Fig. 5 a, bottom right; and Fig. S3). These observations were consistent with late-stage megakaryocyte death, but did not absolutely prove an intrinsic physiological dependence upon $\mathrm{Bcl}-\mathrm{x}_{\mathrm{L}}$, given the associated dramatic reduction in platelet life span and platelet number exhibited by $B c l-x^{P f 4 \Delta / P f 4 \Delta}$ mice.

To establish whether megakaryocytes lacking $\mathrm{Bcl}-\mathrm{x}_{\mathrm{L}}$ could produce platelets normally in the absence of severe thrombocytopenic stress, we generated BM chimeras by transplanting 50:50 ratios of $B c l-x^{+/+}$or $B c l-x^{P f 4 \Delta / P f 4 \Delta}$ BMCs with wild-type GFP-expressing

Figure 4. Megakaryocytes require $\mathrm{Bcl}-\mathrm{x}_{\mathrm{L}}$ for survival during platelet formation. Proplatelet formation (a) and viability (b) of cultured fetal liver-derived MGKs harboring a constitutive or conditional deletion of $B C l-x$. Data represent mean $\pm \mathrm{SEM}$. $B \mathrm{Cl}-x^{+/+}, n=7$; $B C l-x^{-/-}, n=8 ; B C l-x^{f / / f l}, n=18$; and $B C l-x^{P f 4 \Delta / P f 4 \Delta}$, $n=13$ technical replicates. $n=3$ biological replicates for $B \mathrm{Cl}-x^{-/-} ; n=5$ for $B C l-x^{P f 4 \Delta / P f 4}$ and corresponding controls. (c) Representative still images from time-lapse video microscopy of cultured fetal liver-derived $B C l-\chi^{f f / f l}$ (Video 1) and $B C l-x^{p f 4 \Delta / P f 4 \Delta}$ (Video 2) MGKs. Frames were captured every minute for $24 \mathrm{~h}$. Videos run at 25 frames/s. Videos start at $10.7 \mathrm{~h}$ (Video 1) and $1.3 \mathrm{~h}$ (Video 2). Time (h). Bar, $100 \mu \mathrm{m}$. (d) Representative still images from time-lapse video microscopy of cultured fetal liver-derived $B C l-X^{-+/+}$(Video 3) and BCl-X $x^{P f 4 \Delta / P f 4 \Delta}$ (Video 4) MGKs binding Alexa Fluor 488-conjugated Annexin V (green). Frames were captured every $15 \mathrm{~min}$ for $24 \mathrm{~h}$. Videos run at 6 frames/s. Time (h). Bar, $100 \mu \mathrm{m}$. 
BMCs into lethally irradiated adult recipients. 7 wk after transplant, recipients of $\mathrm{Bcl}-x^{+/+} / \mathrm{GFP}$ BMCs had platelet counts of $959 \pm 145$, and recipients of $B c l-x^{P f 4 \Delta / P f 4 \Delta / G F P}$ had platelet counts of $354 \pm 69$, an $\sim 16$-fold increase relative to $B c l-x^{P f 4 \Delta / P f 4 \Delta}$ mice (Fig. 5 b, left). As expected, given their short life span, $<10 \%$ of platelets in recipients of $B c l-x^{P f 4 \Delta / P f 4 \Delta /}$ GFP BMC were GFP $^{-v e}$ (Fig. 5 b, middle). In both models, wild-type platelet morphology, whether $\mathrm{GFP}^{+\mathrm{ve}}$ or $\mathrm{GFP}^{-\mathrm{ve}}$, was normal (Fig. 5 b, right). In contrast, $B c l-x^{P f 4 \Delta / P f 4 \Delta} \mathrm{GFP}^{-v e}$ platelets displayed the same disturbed morphological profile as those from unmanipulated $B c l-x^{P f 4 \Delta / P f 4 \Delta}$ mice (Fig. 5 b). Thus, even in the absence of the severe thrombocytopenic stress, megakaryocytes lacking $\mathrm{Bcl}-\mathrm{x}_{\mathrm{L}}$ undergo an abnormal platelet shedding process. Collectively, these data demonstrate that megakaryocytes are dependent on $\mathrm{Bcl}-\mathrm{x}_{\mathrm{L}}$ to maintain survival during platelet shedding.

\section{Inhibition of $\mathrm{Bcl}-\mathrm{x}_{\mathrm{L}}$ triggers megakaryocyte apoptosis}

To more fully understand the death process in $B c l-x^{P f 4 \Delta / P f 4 \Delta}$ megakaryocytes, we measured apoptotic effector caspase activity in mature, unmanipulated FLC-derived cells. Bcl- $x^{-/-}$ and $B c l-x^{P f 4 \Delta / P f 4 \Delta}$ megakaryocytes exhibited a fivefold increase in the activity of caspase-3/7 (Fig. 6 a) and -9 (not depicted) relative to $\mathrm{Bcl}-x^{+/+}$and $B c l-x^{f / f l}$ counterparts. ATP levels, a marker of mitochondrial function, were dramatically decreased after 24 h of culture (Fig. 6 b). These results are consistent with loss of $\mathrm{Bcl}-\mathrm{x}_{\mathrm{L}}$ inducing the intrinsic apoptosis cascade. We then asked whether pharmacological inhibition of Bcl- $\mathrm{x}_{\mathrm{L}}$ could achieve the same effect. Wild-type FLC- and BM-derived mature megakaryocytes were incubated with the small molecule ABT-737, a BH3 mimetic drug that antagonizes $\mathrm{Bcl}-\mathrm{x}_{\mathrm{L}}$ and the related prosurvival proteins $\mathrm{Bcl}-2$ and Bcl-w (Oltersdorf et al., 2005). After 5 h, a sixfold increase in caspase activity and a concomitant reduction in ATP levels were observed (Fig. 6, c and d). ABT-737 inhibited proplatelet formation in a dose-dependent manner (Fig. 6 e). Collectively, these data indicate that genetic deficiency or pharmacological inhibition of $\mathrm{Bcl}-\mathrm{x}_{\mathrm{L}}$ triggers the intrinsic apoptosis pathway, leading to caspase activation and failure of proplatelet formation. We conclude that caspase activation has a negative impact on the ability of megakaryocytes to produce platelets. This runs counter to previous studies suggesting that megakaryocytes require apoptotic caspases to facilitate platelet shedding (De Botton et al., 2002; Clarke et al., 2003).

We therefore examined the role of caspases in proplatelet formation more closely. Wild-type megakaryocytes were incubated with two distinct broad-spectrum caspase inhibitors, z-VAD.fmk (Dolle et al., 1994) and Q-VD-OPh (Caserta et al., 2003). In agreement with previous studies, cells cultured with high doses of z-VAD.fmk exhibited a significant impairment of proplatelet formation and loss of viability (Fig. 6, $\mathrm{f}$ and $\mathrm{g})$. In contrast, neither effect was observed with Q-VD-OPh (Fig. 6, f and g). In fact, proplatelets formed by megakaryocytes treated with Q-VD-OPh exhibited a similar increase in stability and survival to those formed by $\mathrm{Bak} \mathrm{k}^{-/-}$ $B a x^{-1-}$ megakaryocytes (Fig. 2, a and b). Because Q-VD$\mathrm{OPh}$ did not impair proplatelet formation or viability, we tested whether it could ameliorate the effects of ABT-737 on wild-type megakaryocytes. Interestingly, although preincubation with Q-VD-OPh could hinder the loss of mitochondrial function triggered by ABT-737 (Fig. 7 a), it did not rescue proplatelet formation (unpublished data). Collectively, these data indicate that activation of the intrinsic apoptosis pathway induces mitochondrial damage and caspase activation, resulting in failure of platelet shedding and cell death.
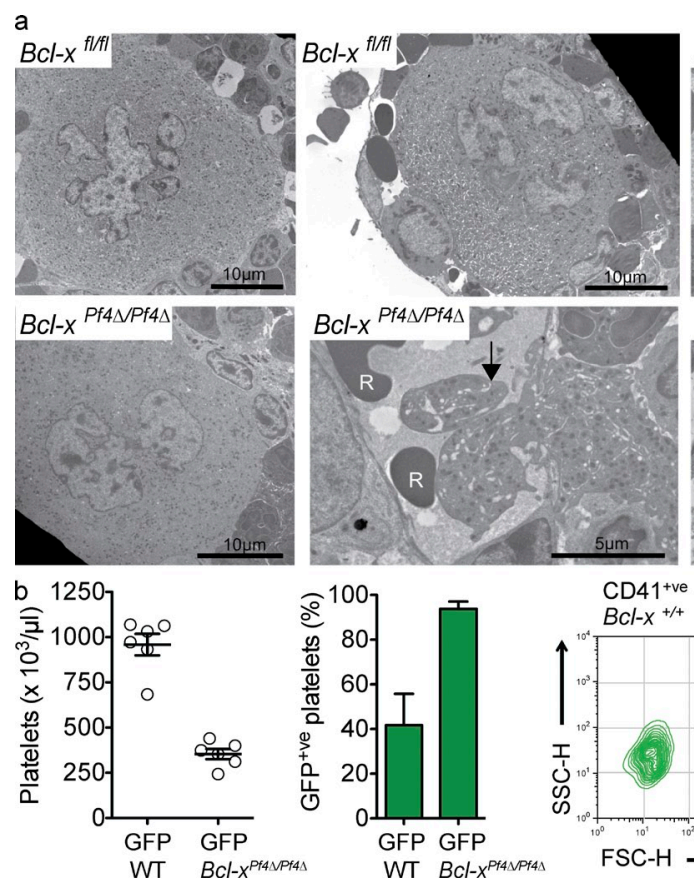
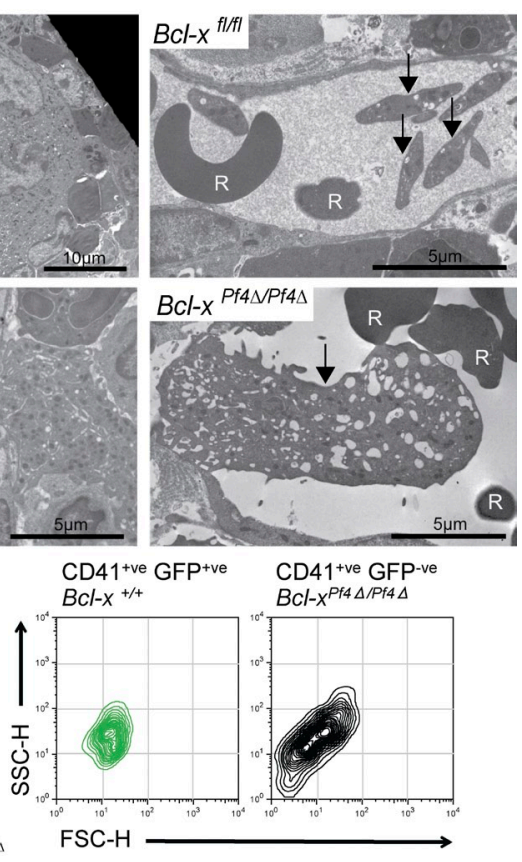

$\mathrm{BCl}-\mathrm{x}^{+/+}$

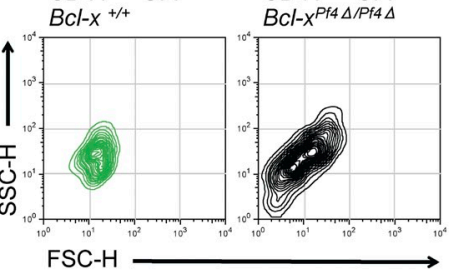

\section{Deletion of Bak and Bax protects} megakaryocytes from apoptotic signals

Bak and Bax are the gatekeepers of the intrinsic apoptosis pathway in a wide range of cells, including platelets. We therefore asked whether

Figure 5. Platelet production is abnormal in the absence of $\mathbf{B c l}-\mathbf{x}_{\mathrm{L}}$. (a) Representative transmission electron microscope images of BM sections showing aberrant MGK morphology and abortive platelet shedding in $\mathrm{BCl}-x^{\mathrm{Pf} 4 \Delta / P f 4 \Delta}$ mice. Arrows indicate normal platelets in wild-type and large megakaryocyte-derived fragments in $B C l-x^{P f 4 \Delta / P f 4 \Delta}$ animals. Red blood cell (R). Bars: 5 or $10 \mu \mathrm{m}$, as indicated. See Fig. S3 for higher magnification images. (b) Mice reconstituted with a 50:50 mixture of $B C l-x^{P f 4 \Delta / P f 4 \Delta}$ and wild-type GFP-expressing BMCs. (left) Platelet counts in peripheral blood 7 wk after transplant, mean \pm SEM. (middle) Percent CD41+ve GFP+ve platelets; mean \pm SD. $n=6$. (right) Flow cytometric forward and side scatter plots of CD41+ve platelets in PRP. In these mice, GFP+ve platelets were produced by wild-type MGKs, GFP-ve platelets by $B C l-x^{P f 4 \Delta / P f 4 \Delta} M G K s$. Plots are representative of $n=6$ recipient mice per transplant group. 

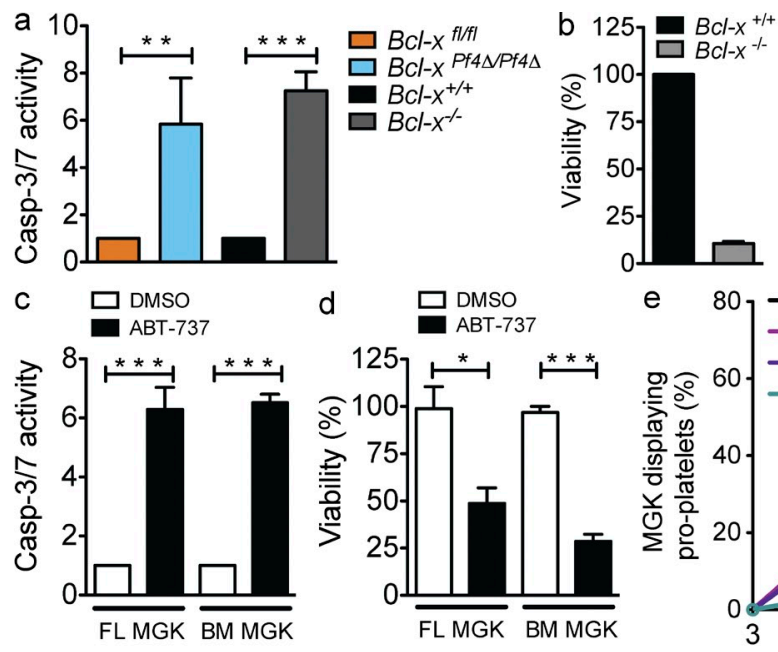

e 807 - DMSO
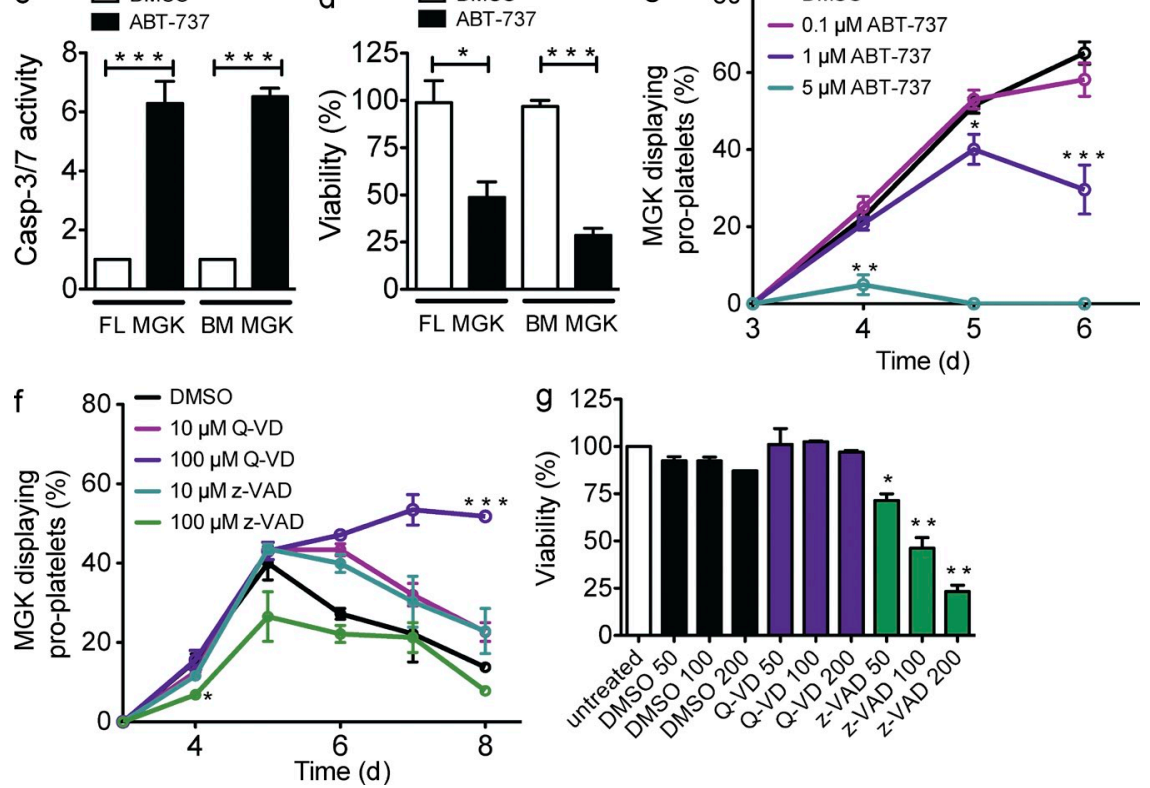

Figure 6. Genetic or pharmacological inhibition of Bcl- $x_{L}$ causes megakaryocyte apoptosis. (a) Caspase-3/7 activity in FLC-derived MGKs. Fetal livers were cultured in serum free media plus TPO for $3 \mathrm{~d}$. Large MGKs were purified from a BSA-gradient and reseeded. $5 \mathrm{~h}$ later, caspase activity was measured using the Caspase-Glo assay system. Data represent fold increase compared with control \pm SEM. $n=2$ biological replicates for each genotype. (b) Viability of MGKs derived from fetal liver was measured $24 \mathrm{~h}$ after reseeding using the CellTiter-Glo assay system. Data represent mean \pm SD. $n=3$ independent experiments. Control was set as 100\%. (c and d) MGKs derived as in a from fetal liver (FL) or BM (BM) were treated with $\mathrm{ABT}-737(5 \mu \mathrm{M})$ or vehicle (DMSO) in serum-free media plus TPO. (c) Caspase-3/7 activity was measured after $5 \mathrm{~h}$. Data represent fold increase compared with DMSO control. $n=6$ independent experiments for $\mathrm{FL} ; n=3$ for BM. (d) Viability after 24 h. $n=4$ independent experiments. DMSO control was set as 100\%. MGK were pooled from animals of same genotype. Mean \pm SEM (e) Proplatelet formation by wild-type fetal liver-derived MGKs treated with ABT-737 or vehicle (DMSO). Data represent mean \pm SEM. $n=6$ technical replicates (except $5 \mu \mathrm{M}$, $n=2$ ). Representative of three independent experiments. (f) Proplatelet formation by wild-type, FLC-derived MGKs treated with caspase inhibitors z-VAD.fmk or Q-VD-OPh or vehicle (DMSO). Data

represent mean \pm SEM, $n=2$ technical replicates. Representative of three independent experiments. (g) Viability of MGKs incubated with z-VAD.fmk, $\mathrm{Q}-\mathrm{VD}-\mathrm{OPh}$, or vehicle (DMSO). Cells were derived as in a from fetal liver and reseeded with the relevant agent. Viability was measured $24 \mathrm{~h}$ after reseeding using the CellTiter-Glo assay system. Untreated control was set as 100\%. Data represent mean \pm SD. $n=2$ technical replicates in two independent experiments. ${ }^{*}, \mathrm{P}<0.05 i^{* *}, \mathrm{P}<0.005 ;{ }^{* * *}, \mathrm{P}<0.0001$.

they mediate megakaryocyte death in response to proapoptotic stimuli. Mature fetal liver- and BM-derived megakaryocytes were exposed to three compounds that are known to induce the intrinsic apoptosis pathway in other cell types: ABT-737, the topoisomerase II inhibitor etoposide, and the broad-spectrum kinase inhibitor STS. In wild-type cells, all three compounds induced a dramatic reduction in ATP levels (Fig. 7 a and Fig. S4) and a concomitant increase in apoptotic caspase activity (Fig. 7 b). This was accompanied by failure of proplatelet formation (Fig. 7 c). Strikingly, in the case of ABT-737, genetic deletion of Bak and Bax could completely rescue megakaryocytes from these effects. Viability, caspase activity, and proplatelet formation were all normal in $\mathrm{Bak}^{-/-} \mathrm{Bax}^{-/-}$ megakaryocytes treated with the drug (Fig. 7, a-c; and Fig. S4). Interestingly, $B a k^{-/-} B a x^{-/-}$megakaryocytes were protected from etoposide also, but still exhibited an impairment of proplatelet formation (Fig. 7, a-c). This was in contrast to the effects of STS, which were in no way ameliorated by loss of the prodeath proteins (Fig. $7, \mathrm{a}-\mathrm{C}$ ).

To examine whether loss of Bak and Bax could protect the megakaryocyte lineage in vivo, we first deleted Bak and $B a x$ in $B c l-x^{P f 4 \Delta / P f 4 \Delta}$ mice. In agreement with Kodama et al. (2011), we found that single deficiency of either protein had no effect. In contrast, Bak/Bax double deficiency completely rescued the defects in platelet production caused by loss of Bcl- $\mathrm{x}_{\mathrm{L}}$ (Fig. 7 d). This encouraged us to examine the role of Bak and Bax in chemotherapy-induced thrombocytopenia, specifically carboplatin, an agent with a well-described propensity to cause thrombocytopenia in patients (Budd et al., 1999). Given that carboplatin, along with many other standard chemotherapeutics, is thought to kill both megakaryocytes and their progenitors (Zeuner et al., 2007), we generated wild-type and $\mathrm{Bak}^{-/-} \mathrm{Bax}^{-/-}$FLC-reconstituted animals. At 8 wk after transplantation, these were treated with a single dose of carboplatin. Loss of Bak and Bax significantly ameliorated both the thrombocytopenia (Fig. 7 e) and anemia (Fig. $7 \mathrm{f}$ ) triggered by the drug.

\section{DISCUSSION}

Our studies demonstrate that megakaryocytes possess an intrinsic apoptosis pathway, the key components of which are prosurvival $\mathrm{Bcl}-\mathrm{x}_{\mathrm{L}}$, and prodeath $\mathrm{Bak}$ and Bax. Contrary to the widely accepted model, this pathway is not activated by megakaryocytes to facilitate platelet shedding. Deletion of Bak and Bax, the gatekeepers of the intrinsic apoptosis pathway, had no adverse effect on megakaryocyte number, ploidy, 

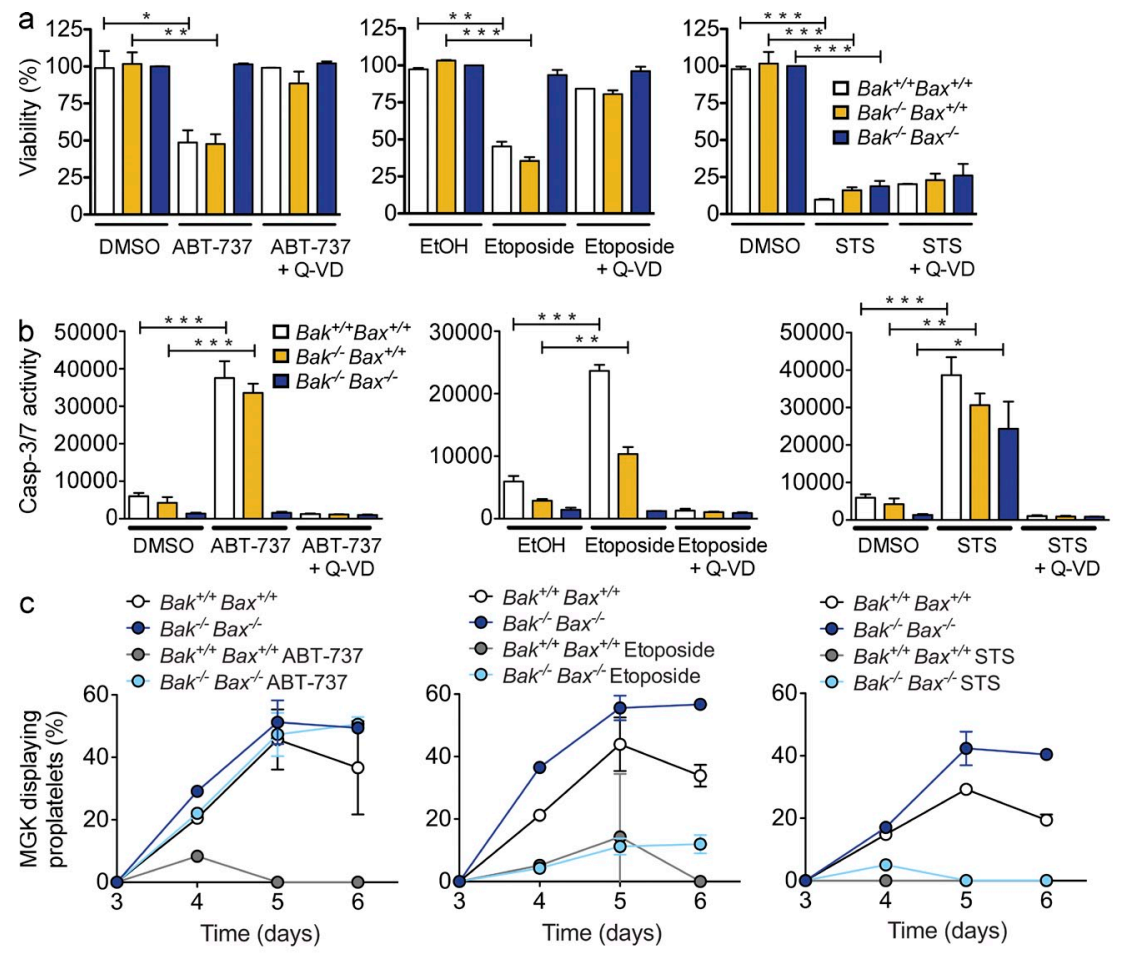

$$
\begin{aligned}
& \text { - } \mathrm{Bak}^{+/+} \mathrm{Bax}^{+/+} \\
& \text {- } \mathrm{Bak}^{-/} \mathrm{Bax}^{-/} \\
& \text {- } \mathrm{Bak}^{+/+} \mathrm{Bax}^{+/+} \text {STS }
\end{aligned}
$$$$
600 \mathrm{Bak}^{-1-B^{-1} \mathrm{STS}}
$$
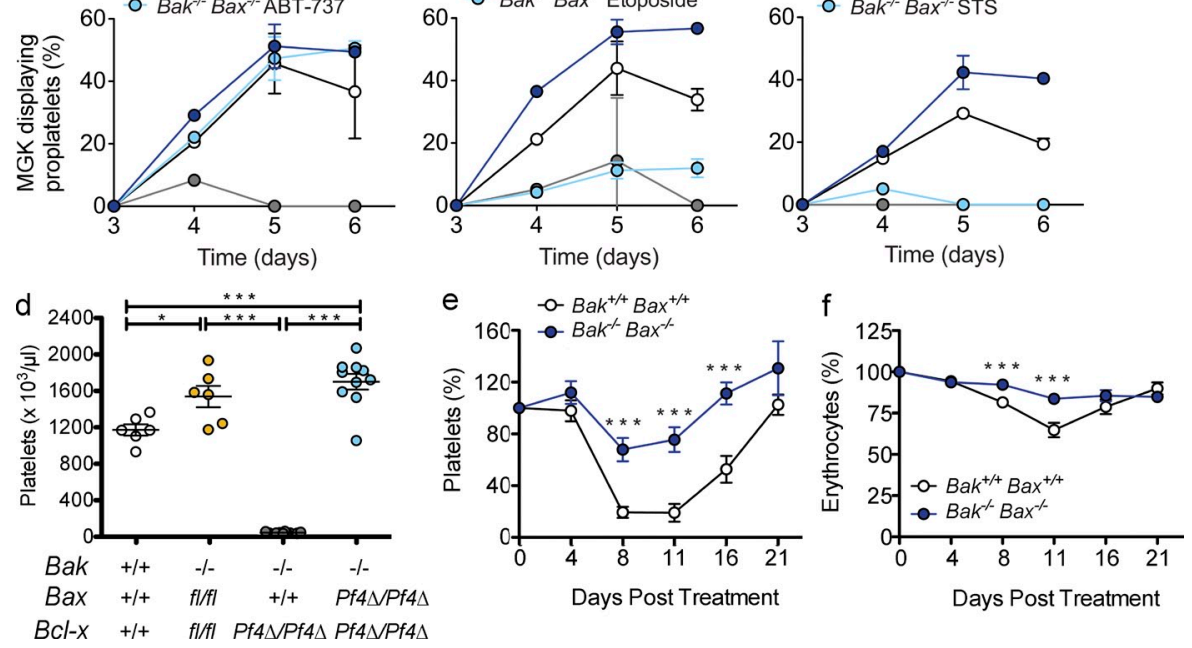

or proplatelet formation. Platelet production at steady state, or in response to experimentally induced thrombocytopenia, was normal. This was true whether Bak and Bax were conditionally or constitutively deleted from the megakaryocyte lineage. The only abnormality we observed was an increase in the number of naked megakaryocyte nuclei when both Bak and Bax were deleted. Although apparent at steady state, the phenomenon was much more pronounced during recovery from thrombocytopenia. This suggests that Bak and Bax mediate the clearance of the megakaryocyte nucleus after platelet shedding. Whether or not this is an apoptotic process is unclear. It is certainly possible; we observed a thin ring of cytoplasm around naked nuclei, perhaps this is normally the site of postshedding apoptosis designed to ensure swift engulfment. In support of this notion, our live cell imaging data demonstrated that, in vitro, wild-type megakaryocytes expose significant levels of PS once proplatelet formation is complete.

In stark contrast to their absence, the activation of Bak and Bax had a profound and detrimental impact on megakaryocytes. Wild-type cells treated in vitro with the proapoptotic agent $\mathrm{ABT}-737$, which inhibits $\mathrm{Bcl}-\mathrm{x}_{\mathrm{L}}, \mathrm{Bcl}-2$, and $\mathrm{Bcl}-\mathrm{w}$ (Oltersdorf et al., 2005), suffered mitochondrial damage, caspase cytes lacking Bcl- $\mathrm{x}_{\mathrm{L}}$.
Figure 7. Deletion of Bak and Bax protects megakaryocytes from death signals. (a) Viability of Bak- and Bax-deficient MGKs in response to ABT-737, etoposide, and STS. Mature FLC-derived MGKs were purified from a BSA gradient and cultured in serum-free media with TPO and either ABT-737 $(5 \mu \mathrm{M})$, Etoposide $(50 \mu \mathrm{M})$, STS $(10 \mu \mathrm{M})$, vehicle controls DMSO (0.05\% ABT-737, 1\%, STS), or ethanol (EtOH) $0.27 \%$, or in combination with Q-VD-Oph $(50 \mu \mathrm{M})$. Viability was measured $24 \mathrm{~h}$ after reseeding using the CellTiter-Glo assay system. DMSO control-treated $\mathrm{Bak}^{-1-} \mathrm{Bax}^{-/-}$ levels were set as $100 \%$. Data represent mean \pm SEM. $n=3-4$ independent experiments.

(b) Caspase-3/7 activity in MGKs derived and treated as in a. Caspase-Glo assay was conducted $5 \mathrm{~h}$ after reseeding. MGK were pooled from $>4$ animals per genotype. Data represent mean \pm SEM. $n=4$ independent experiments. (c) Proplatelet formation in MGKs derived and treated as in a. Data represent mean $\pm S D$, $n=2$ technical replicates. MGKs were pooled from $>2$ animals per genotype. Representative of two independent experiments. (d) Platelet counts at $7 \mathrm{wk}$ of age in mice lacking $\mathrm{Bcl}-\mathrm{x}_{\mathrm{L}}$, Bak, and Bax in the MGK lineage. Each symbol represents 1 mouse. Data represent mean \pm SEM. $n=6-10$ mice per genotype. (e) Platelet counts in lethally irradiated mice reconstituted with $\mathrm{FLC}$, and injected with a single IP injection of carboplatin $(100 \mathrm{mg} / \mathrm{kg})$ on day 0 . Cohorts of mice (day $8 ; n=13 \mathrm{Bak}^{+/+} \mathrm{Bax}^{+/+}$and $17 \mathrm{Bak}^{-/-} \mathrm{Bax}^{-/-}$; day $11, n=21 \mathrm{Bak}^{+/+} \mathrm{Bax}^{+/+}$ and $24 \mathrm{Bak}^{-/} \mathrm{Bax}^{-/-}$; day 16, $n=13 \mathrm{Bak}^{+/+} \mathrm{Bax}^{+/+}$ and $n=16 \mathrm{Bak}^{-1-} \mathrm{Bax}^{-1-}$ ) were sacrificed at indicated time points. Data represent mean percentage of change to baseline \pm SEM.

activation, and death. A similar phenomenon was observed in mature, unmanip(f) Erythrocyte counts from the experiment presented in e. Data represent mean percentage of change from baseline \pm SEM. ${ }^{*}, P<0.05$; ${ }^{* *}, \mathrm{P}<0.005 ;{ }^{* * *}, \mathrm{P}<0.0001$. In both cases, proplatelet formation failed. Genetic deletion of Bak and Bax could block death and rescue proplatelet formation in the presence of ABT-737, and completely restored platelet production in mice lacking $\mathrm{Bcl}-\mathrm{x}_{\mathrm{L}}$. Thus, megakaryocytes require $\mathrm{Bcl}-\mathrm{x}_{\mathrm{L}}$ to restrain the activity of Bak and Bax during platelet production.

Our data indicate that megakaryocytes become dependent on $\mathrm{Bcl}-\mathrm{x}_{\mathrm{L}}$ just as they enter into proplatelet formation. It is not required for their growth and development, as indicated by the abundance of polyploid megakaryocytes in the BM of $B c l-x^{P f 4 \Delta / P f 4 \Delta}$ mice, and in the yield of large mature cells from cultures of $\mathrm{Bcl}-\mathrm{x}_{\mathrm{L}}-$ deficient $\mathrm{BM}$ and fetal liver. Unlike their wild-type counterparts, however, cultured $B c l-x^{P f 4 \Delta / P f 4 \Delta}$ megakaryocytes are unable to elaborate proplatelets, instead undergoing Bak/Bax-dependent death which is accompanied by significant exposure of PS. Although the situation in vivo is 
more difficult to visualize, there is no doubt that platelet production is disturbed, independently of the severe thrombocytopenia that results from loss of $\mathrm{Bcl}-\mathrm{x}_{\mathrm{L}}$ in platelets. This is demonstrated by the ultrastructural analysis, and also the BM chimera experiments which confirmed that even in the presence of wild-type hematopoiesis, $B c l-x^{P f 4 \Delta / P f 4 \Delta}$ megakaryocytes produce morphologically aberrant platelets.

Clearly, induction of Bak- and Bax-mediated apoptosis results in a failure of platelet shedding, but it appears there are additional mechanisms by which proapoptotic stimuli can block proplatelet formation. Although Bak- and Bax-deficient megakaryocytes were resistant to etoposide-induced mitochondrial damage and caspase activation, they still exhibited a failure of proplatelet formation. This suggests that DNA damage may suppress platelet shedding independently of apoptosis occurring. Etoposide treatment results in DNA double-strand and single-strand breaks (Wozniak and Ross, 1983), which trigger activation of kinase signaling cascades, primarily the ATM-Chk2 and ATR-Chk1 pathways (Cimprich and Cortez, 2008). The role of these pathways in megakaryocytes, and the mechanism by which they might influence proplatelet formation is yet to be established. Interestingly, even in the absence of Bak and Bax, STS, a classical inducer of the intrinsic apoptosis pathway, was able to induce mitochondrial damage and caspase activation in megakaryocytes. This contrasts with $B a k^{-/-} B a x^{-1-}$ mouse embryonic fibroblasts, which are resistant (Wei et al., 2001). These data indicate that megakaryocytes possess additional cell death signaling pathways, and, as Q-VD-OPh could not block STS-induced mitochondrial damage, they are likely to be caspase independent.

Our findings contradict a substantial body of literature which holds that megakaryocytes deliberately use the apoptotic machinery to facilitate platelet production. We believe that many of the apparent discrepancies can be explained. First, several of the key studies reporting that impaired apoptotic signaling diminishes platelet production involved overexpression of Bcl-2 family survival proteins, either in mice or in cell culture (Ogilvy et al., 1999; De Botton et al., 2002; Kaluzhny et al., 2002). Overexpression of any protein can impact on cellular processes in complex and unforeseen ways, and Bcl-2 has been linked to the cell cycle (Vairo et al., 1996), calcium homeostasis (Bassik et al., 2004), autophagy (Pattingre et al., 2005), and inflammasome function (Bruey et al., 2007). Indeed, it has recently been demonstrated that $\mathrm{Bcl}-2$ transgenic mice, which exhibit thrombocytopenia (Ogilvy et al., 1999), recover normal platelet counts upon splenectomy (Kozuma et al., 2009). Second, data from in vitro culture systems, cell lines, and chemical inhibitor studies should be interpreted with caution. Our results agree with previous studies that high concentrations of the caspase inhibitor zVAD.fmk can inhibit proplatelet formation by megakaryocytes (De Botton et al., 2002; Clarke et al., 2003). In contrast, however, we found that the difluorophenoxy-methylketone-based pancaspase inhibitor Q-VD-OPh does not. Wild-type proplatelets in cultures treated with Q-VD-OPh survived significantly longer than untreated counterparts. Given that proplatelets lacking Bak and Bax exhibited a similar increase in stability and survival, we believe the most likely explanation for the discrepancy between the two inhibitors is that high doses of $z$-VAD.fmk trigger caspase-independent toxicity in megakaryocytes. It is known that z-VAD.fmk has potent activity against cathepsins B, H, and L (Chauvier et al., 2007), and in some cells can lead to necrosis (Temkin et al., 2006; Wu et al., 2011). In fact, in 2009 the Nomenclature Committee on Cell Death recommended that the term z-VAD.fmk-inhibitable should be used in preference to "caspase-dependent" (Kroemer et al., 2009).

In addition to the intrinsic apoptosis pathway, the extrinsic pathway has also been implicated in platelet shedding. Treatment of MEG-01 cells with Fas ligand (FasL) or an antiFas agonistic antibody was reported to increase proplatelet formation and production of platelet-like particles (Clarke et al., 2003). Similar results were obtained with primary mouse megakaryocytes or human bone core explants subjected to Fas agonism. This might suggest that although the intrinsic pathway is dispensable for platelet shedding, either the extrinsic pathway alone is required, or a combination of both is essential. Our results with Q-VD-OPh argue against this notion, as Fas signaling is mediated by caspase-8 (Boldin et al., 1996; Fernandes-Alnemri et al., 1996; Muzio et al., 1996) and $\mathrm{Q}-\mathrm{VD}-\mathrm{OPh}$ is an effective inhibitor of this critical initiator (Chauvier et al., 2007). Genetic deletion studies will be required to define the role of the extrinsic apoptosis pathway in megakaryocyte biology.

Our results with carboplatin demonstrate that deletion of Bak and Bax can significantly protect the megakaryocyte lineage against a pathophysiological insult in vivo. Chemotherapy-induced thrombocytopenia (CIT) remains a significant unmet clinical need (Vadhan-Raj, 2009), and it will be interesting to see whether Bak/Bax-mediated killing contributes to CIT caused by other agents. In addition to cytotoxic drugs, it is conceivable the pathway might also be activated by autoantibodies, viral infections such as HIV, or radiation. In support of the latter notion, ablation of Bak and Bax in hematopoietic and endothelial cells was recently shown to protect the BM and increase the survival of mice exposed to 12.5 Gy of whole-body irradiation (Kirsch et al., 2010). Whether loss of Bak and Bax can specifically protect the megakaryocyte lineage against radiation remains to be established.

Because carboplatin causes the death not just of megakaryocytes, but of megakaryoblasts and megakaryocyte progenitors (Zeuner et al., 2007), the protection conferred by loss of Bak and Bax suggests that the intrinsic pathway must be restrained throughout the developing megakaryocyte lineage. Prosurvival proteins expressed in megakaryocytes include Bcl- $\mathrm{x}_{\mathrm{L}}$, Bcl-2, and Mcl-1 (Sanz et al., 2001; Zeuner et al., 2007; this study). One explanation for the fact that loss of Bcl- $\mathrm{x}_{\mathrm{L}}$ only appears to affect megakaryocytes undergoing platelet shedding might be that it is the sole prosurvival protein expressed at this critical juncture. The heterogeneous nature of megakaryocyte cultures makes this a difficult notion to test, and the fact that platelets express Bcl-2 suggests otherwise. Perhaps a 
more likely scenario is that polyploidization, proplatelet formation, and platelet shedding generate acute proapoptotic stresses within the megakaryocyte, which multiple Bcl-2 family prosurvival proteins are required to resist. Loss of $\mathrm{Bcl}-\mathrm{x}_{\mathrm{L}}$ is enough to disturb the pro- and antiapoptotic balance. It will be interesting to see whether deletion of Mcl-1 and Bcl-2 in megakaryocytes results in a similar phenotype. Given that agents specifically targeting Bcl-2 family prosurvival proteins are currently being developed for use in a range of human malignancies (Leber et al., 2010; Petros et al., 2010; Wilson et al., 2010; Roberts et al., In Press), it will be important to understand the contribution they make to the development and survival of the megakaryocyte lineage.

\section{MATERIALS AND METHODS}

Animals. Bak (Lindsten et al., 2000), Bax (Knudson et al., 1995) and Bcl-x (Motoyama et al., 1999) knockout, Bcl-x (Rucker et al., 2000) and Bax (Takeuchi et al., 2005) floxed, Pf4-Cre (Tiedt et al., 2007), and UBC-GFP (Schaefer et al., 2001) transgenic mice have been previously described. All mutations had been backcrossed to wild-type C57BL/6 at least 10 generations before this study. Chimeric animals in which the hematopoietic system was reconstituted with $B a k^{-/-} B a x^{-/-}$FLCs were generated as previously described (Schoenwaelder et al., 2009). All animal experiments complied with the regulatory standards of, and were approved by, the Walter and Eliza Hall Institute (WEHI) Animal Ethics Committee.

Materials. Biotin N-hydroxy-succinimide ester (NHS-biotin), DMSO, thiazole orange, propidium iodide, and STS were purchased from Sigma-Aldrich. ABT-737 was provided by Abbott Laboratories. Q-VD-OPh was purchased from Alexis, Z-VAD (OMe)-FMK was purchased from MERCK Chemicals Ltd., Carboplatin was purchased from Pfizer, and Etoposide was obtained from Mayne Pharma Pty Ltd. Enhanced chemiluminescence system (ECL; Millipore), protease inhibitor cocktail, Complete (Roche), 4-12\% Bis-Tris gels (NuPAGE; Invitrogen), and Spherotech calibration beads 3.5-4.0 $\mu \mathrm{m}$ (Spherotech Inc.).

Antibodies. X488, fluorescently conjugated-GPIb $\alpha$ (Xia.G5),-GPIX (Xia. B4), and -GPVI (JAQ1) were obtained from Emfret Analytics $\mathrm{GmbH}$ and Co. KG; FITC-, PE-, or APC-conjugated anti-mouse, CD41 (clone MWReg30), TER-119, CD45.1 (A20), CD45.2, CD45R/B220 (RA3-6B2), fluorescently conjugated streptavidin, Annexin V, nonconjugated mouse antiBcl-xl (clone 44), and mouse anti-Bcl-2 (clone 7) were purchased from $\mathrm{BD}$; rabbit polyclonal anti-bak, anti- $\alpha$-tubulin, and anti-actin-HRP were obtained from Sigma-Aldrich; rabbit polyclonal anti-bax were from (Millipore); and rat anti-Mcl-1 (clone 19C4-15) was obtained from WEHI (Parkville, Australia) mAb Facility.

Hematology. Automated cell counts were performed on blood collected from the retroorbital plexus into Microtainer tubes containing EDTA (Sarstedt), using an Advia 2120 hematological analyser (Siemens). Platelet counts in diluted whole blood were determined by flow cytometry with Sphero blank calibration particles $(3.5-4.0 \mu \mathrm{m}$; Spherotech Inc.) and gating on CD $41^{+ \text {ve }}$ and TER-119-ve cells. Megakaryocytes were counted manually in sections of sternum and spleen stained with hematoxylin and eosin with a minimum of 10 high power fields $(200 \times)$ analyzed. Peripheral blood smears were stained with May Grunwald Giemsa. Hematopoietic progenitors were cultured as previously described (Alexander et al., 1996). Acute thrombocytopenia was induced by antiplatelet serum and assessed as previously described (Mason et al., 2007).

Megakaryocyte culture from fetal livers and BM. E13.5 embryos (or E12.5 when indicated) were harvested into cold DME Kelso, 10\% FCS. Fetal livers were dissected out, and cell suspensions were prepared in PBS. BM was harvested from murine bones and flushed into DME Kelso, 10\% FCS. Red cells were lysed, and the nucleated cells were counted. The cells were lineage depleted by incubation with a mix of antibodies (CD4, CD2, CD3, CD5, CD8, CD11b, erythroid, CD19, Gr-1, B220/CD45R; WEHI) in KDS BSS $2 \%$ FCS, followed by goat anti-rat IgG magnetic beads (Bio Mag; QIAGEN). $5 \times 10^{5}$ cells $/ \mathrm{ml}$ were seeded in 6 -well plates into serum-free media (SFM; Norol et al., 1998) supplemented with $100 \mathrm{ng} / \mathrm{ml}$ murine TPO (WEHI). Cells were cultured for $3-5 \mathrm{~d}$ at $37^{\circ} \mathrm{C}, 5 \% \mathrm{CO}_{2}$. To isolate dense, viable, mature megakaryocytes, cells were overlaid on a discontinuous BSA (BSA Fraction V; Invitrogen) density gradient (3,1.5, and 0\%; Drachman et al., 1997), and cells were harvested in the $3 \%$ layer.

Proplatelet formation assay. Large fetal liver or BM derived megakaryocytes were seeded in 96-well plates 300-500 cells/well into SFM supplemented with TPO. Cells were cultured with or without the addition of ABT-737 $(5 \mu \mathrm{M})$, etoposide $(50 \mu \mathrm{M})$, STS $(10 \mu \mathrm{M})$, Q-VD-OPh $(50 \mu \mathrm{M})$, vehicle controls DMSO, and ethanol if not otherwise stated. Megakaryocytes displaying proplatelets were counted by microscopy and percentage was calculated by dividing the number of proplatelet forming megakaryocytes with the total number of cells each day. Percentage of live megakaryocytes in Fig. 4 b was quantified by dividing the total cell number each day (proplatelet forming megakaryocytes + non proplatelet forming megakaryocytes) with the number of megakaryocytes at day 3 .

Megakaryocyte receptor expression. E13.5 (or E12.5 where stated) FLCs were cultured in SFM and TPO for 3-5 d. The cells were stained with CD41 or negative control for $30 \mathrm{~min}$ on ice before washing and analysis on a FACSCalibur flow cytometer (BD). Megakaryocytes were also isolated for PCR analysis. In brief, FLCs were cultured in TPO for 1, 2, or $3 \mathrm{~d}$ and $\mathrm{CD}_{4} 1^{+}$and propidium iodide ${ }^{-}$cells were sorted on MoFlo flow cytometer. Sorted megakaryocytes were lysed and used for PCR.

Megakaryocyte ploidy. BM was harvested from $8-10-w k-o l d ~ m i c e$, or 8 wk after BM reconstitution, and megakaryocyte ploidy was studied with propidium iodide as previously described (Kruse et al., 2009).

Serum TPO. Serum TPO levels were measured using the Quantikine Mouse TPO Immunoassay kit (R\&D Systems) according to the manufacturer's instructions.

Caspase activity and viability assays. Megakaryocytes were harvested from BSA gradients, counted, and reseeded in SFM with TPO into 96-well plates, and then returned to the $37^{\circ} \mathrm{C}$ incubator after the addition of ABT$737(5 \mu \mathrm{M})$, etoposide $(50 \mu \mathrm{M})$, STS $(10 \mu \mathrm{M}), \mathrm{Q}-\mathrm{VD}-\mathrm{OPh}(50 \mu \mathrm{M})$, or vehicle controls DMSO and ethanol if not otherwise stated. Caspase-Glo 3/7 reagents (Promega) were added to the cells after $5 \mathrm{~h}$. The luminescence of each sample was determined in a plate-reading LumiSTAR Galaxy luminometer (BMG Labtech) as directed by manufacturer. Alternatively, Celltiter Glo reagents (Promega) were added after $24 \mathrm{~h}$ to determine cell viability by measuring ATP levels.

Video microscopy. Megakaryocytes were generated as detailed in the proplatelet formation assay and transferred to optically transparent ibiTreat tissue culture treated sterile $\mu$-slide 8 -well (Ibidi) or 96-well optical bottom plates (Nunc). Experiments were performed on a Live Cell Observer with a fully motorized Axiovert 200 inverted microscope (Carl Zeiss, Inc.) driven by the Axiovision 4.7 software (Carl Zeiss, Inc.). Cells were maintained on the stage within a humidified chamber at $37^{\circ} \mathrm{C}$ and $5 \% \mathrm{CO}_{2}$. Time-lapse images were acquired for $24 \mathrm{~h}$ with an AxioCam MRm camera (Carl Zeiss, Inc.) using a $20 \times / 0.8$ objective. Some experiments were performed with a $0.63 \times$ $\mathrm{C}$-mount in place of the $1 \times \mathrm{C}$-mount to increase the camera field of view. In some experiments, $\mathrm{CaCl}_{2}(0.5 \mathrm{mM})$ and Alexa Fluor-488 conjugated Annexin V (1/100) were added immediately before commencing timelapse images. 
Platelet preparation. Blood was obtained by cardiac puncture into 0.1 volume of Aster Jandl (Aster and Jandl, 1964) citrate-based anticoagulant ( $85 \mathrm{mM}$ sodium citrate, $69 \mathrm{mM}$ citric acid, and $20 \mathrm{mg} / \mathrm{ml}$ glucose, $\mathrm{pH} 4.6$ ). Mouse PRP was obtained by centrifugation of the murine blood at $125 \mathrm{~g}$ for $8 \mathrm{~min}$, followed by centrifugation of the supernatant buffy coat at $125 \mathrm{~g}$ for $8 \mathrm{~min}$. Mouse platelets were washed by two sequential centrifugations at $860 \mathrm{~g}$ for $5 \mathrm{~min}$ in $140 \mathrm{mM} \mathrm{NaCl}, 5 \mathrm{mM} \mathrm{KCl}, 12 \mathrm{mM}$ trisodium citrate, $10 \mathrm{mM}$ glucose, and $12.5 \mathrm{mM}$ sucrose, $\mathrm{pH} 6.0$ (buffer A). The platelet pellet was resuspended in $10 \mathrm{mM}$ Hepes, $140 \mathrm{Mm} \mathrm{NaCl}, 3 \mathrm{mM} \mathrm{KCl}, 0.5 \mathrm{mM} \mathrm{MgCl}$, $10 \mathrm{mM}$ glucose, and $0.5 \mathrm{mM} \mathrm{NaHCO}$, $\mathrm{pH} 7.4$ (buffer B). Alternatively, PRP was stained with CD41 or negative control for $20 \mathrm{~min}$ at room temperature before dilution in buffer $\mathrm{B}$ and analysis on a FACSCalibur flow cytometer. FlowJo software (Tree Star) was used to determine platelet forward and side scatter profiles $\left(\mathrm{CD} 41^{+}\right.$cells).

Platelet turnover studies. Platelet life span was assessed with the biotinylation assay as previously described (Heilmann et al., 1993; Mason et al., 2007). Alternatively, platelet-specific X488 was injected intravenously, and platelet life span was measured as previously described in PRP by flow cytometry (Dowling et al., 2010). In addition, platelet life span was determined by X488 in whole blood by flow cytometry gating on CD $41^{+ \text {ve }}$ cells. Platelet transfusion of biotinylated platelets from reconstituted mice ( $8 \mathrm{wk}$ after) into wildtype animals were performed as previously described (Mason et al., 2007).

Platelet receptor expression. PRP was stained with platelet-specific antibodies or negative controls for $20 \mathrm{~min}$. Samples were diluted with buffer $\mathrm{B}$ and directly acquired by flow cytometry. Annexin $\mathrm{V}$ binding was measured in PRP by incubation with fluorescently conjugated Annexin V (20 min) in Annexin $\mathrm{V}$ buffer (Invitrogen), followed by dilution with Annexin $\mathrm{V}$ buffer and direct acquisition by flow cytometry. Reticulated platelets were enumerated as previously described (Mason et al., 2007; Matic et al., 1998).

SDS-PAGE and Western blot analysis. Platelets and megakaryocytes were lysed in NP-40 lysis buffer (Josefsson et al., 2005) or RIPA buffer, respectively. Proteins were separated on $4-12 \%$ Bis-Tris gels (NuPAGE; Invitrogen) under reducing conditions, transferred onto Immobilon-P membranes (Micron Separation), and immunoblotted with various antibodies, followed by secondary HRP-conjugated antibodies and ECL.

Electron microscopy. Transmission electron microscopy was performed after fixation and decalcification of murine femurs, as previously described (Kruse et al., 2009).

Splenectomy procedure. Recipient male mice on a CD45.1 background were splenectomized when 8 wk old. The mice were anaesthetized and a small incision was made in the skin. The peritoneal membrane was opened to expose the spleen. The spleen was surgically removed intact, and wounds were sealed with sutures (peritoneum) and wound clips (skin). The same mice were irradiated and transplanted 3-4 wk after surgery. 8 wk later, donor contribution to peripheral blood leukocytes was analyzed by flow cytometry.

GFP BM chimeras. We generated BM chimeric mice by transplanting 50:50 ratios of CD45.2 Bcl- $x^{+/+}$or Bcl- $x^{P f 4 \Delta / P f 4 \Delta}$ BMCs with CD45.2 UBCGFP (Schaefer et al., 2001) BMCs $\left(2 \times 10^{6}\right.$ cells total per recipient) into lethally irradiated adult CD45.1 congenic C57BL/6 recipients. 7 wk after transplant, we measured total blood cell counts, determined chimerism by measuring CD45.1 and CD45.2 peripheral blood leukocytes, and measured the percentage of $\mathrm{GFP}^{+\mathrm{ve}}$ leukocytes and $\mathrm{CD} 41^{+\mathrm{ve}}$ platelets. Platelet morphology was compared from forward and side scatter plots of CD $41^{+ \text {ve }}$ platelets from the same animal being $\mathrm{GFP}^{+v e}$ (wild-type) or negative $\left(B c l-x^{f / / f}\right.$ or $\left.B c l-x^{P f 4 \Delta / / P f 4 \Delta}\right)$.

Calculated platelet production rates. Rates were calculated by fitting the lognormal-senescent model to platelet survival curves, and using the steadystate relationship: platelet count $=($ production rate $) \times($ mean life span $)$
(Dowling et al., 2010). Statistical uncertainty was assessed using a Monte-Carlo bootstrap resampling technique (20 estimates of the production rate are plotted, horizontal line is the median; Chernick, 1999; Dowling et al., 2010).

Statistical analyses. Statistical significance between two treatment groups was analyzed using an unpaired Student's $t$ test with two-tailed p-values. One-way ANOVA with Boferroni's multiple comparison test was applied where appropriate (GraphPad Prism Software). *, P < 0.05; **, P < 0.005 ; ***, $\mathrm{P}<0.0001$ or as otherwise stated. Data are presented as mean \pm SEM or SD (where indicated).

Online supplemental material. Fig. S1 shows hematopoietic analysis of Bak/Bax BM chimeric mice. Fig. S2 shows characterization of the hematopoietic compartment in mice deficient in Bcl-x in the megakaryocytic lineage. Fig. S3 displays transmission electron microscope images of BM megakaryocytes lacking $B c l-x$. Fig. S4 shows increased viability of Bak/Bax-deficient BM-derived megakaryocytes in response to apoptotic stimuli. Videos 1 and 2 show proplatelet formation by $B c l-x^{f / / f l}$ control or $B c l-x^{P f 4 \Delta / P f 4 \Delta}$ megakaryocytes, respectively. Videos 3 and 4 show PS exposure visualized by Annexin V-Alexa Fluor 488 in green during proplatelet formation by $\mathrm{Bcl}-\mathrm{x}^{+/+}$control or $B c l-x^{P f 4 \Delta / P f 4 \Delta}$ megakaryocytes, respectively. Online supplemental material is available at http://www.jem.org/cgi/content/full/jem.20110750/DC1.

We thank Jason Corbin, Ladina Di Rago, Sandra Mifsud, Cameron Wells, Craig Hyland, Delphine Merino, Monica Yabal, Maria Kauppi, Marion Lebois, and Robyn Sutherland for excellent technical assistance and advice; Shauna Ross, Stephanie Green, Chris Evans, Kelly Trueman, Emma Lanera, Danielle Cooper, Giovanni Siciliano, Kate McKenzie, and Jaclyn Gilbert for outstanding animal husbandry; and Cassandra Vandenberg, Ben Croker, and Jack Levin for insightful discussions. We thank Warren Alexander, Douglas Green, Lothar Hennighausen, Stanley Korsmeyer, Tullia Lindsten, Noboru Motoyama, Radek Skoda, Andreas Strasser, and Craig Thompson for providing mouse strains, and Abbott Laboratories for supplying ABT-737.

This work was supported by Project Grants $(516725,575535)$, Program Grants (461219, 461221), Fellowships (M.R. Dowling, L.A. O'Reilly, A.W. Roberts, D.C.S. Huang and B.T. Kile) and an Independent Research Institutes Infrastructure Support Scheme Grant (361646) from the Australian National Health and Medical Research Council (NHMRC); Fellowships from the Sylvia and Charles Viertel Foundation (B.T. Kile), the Leukaemia Foundation (M.J. White), the Leukemia and Lymphoma Society (E.C. Josefsson), the Swedish Research Council (E.C. Josefsson), NHMRC/Institut National de la Santé et de la Recherche Médicale (C. James), EMBO (C. James), the Victorian Cancer Agency (K.D. Mason and A.W. Roberts), and the Cancer Council of Victoria (D. Metcalf); the Australian Cancer Research Fund, and a Victorian State Government Operational Infrastructure Support Grant.

Author contributions: E.C. Josefsson, C. James, A.W. Roberts, D.C.S. Huang and B.T. Kile designed research, analyzed data, and wrote the paper. E.C. Josefsson, C. James, K.J. Henley, M.A. Debrincat, S. Ellis, K.L. Rogers, R.M. Lane, K.D. Mason, M.R. Dowling, L.A. O'Reilly, E.A. Kruse, M.J. White, D. Metcalf, and P. Nurden performed research and analyzed data.

The Walter and Eliza Hall Institute of Medical Research has an ongoing research collaboration agreement with Genentech in the field of $\mathrm{BCl}-2$ family proteins. A.W. Roberts is an investigator on three clinical trials funded by Abbott and Genentech, and receives funding for laboratory research that is part of those trials. The work described in this manuscript was not funded by either Abbott or Genentech.

Submitted: 14 April 2011

Accepted: 22 August 2011

\section{REFERENCES}

Alexander, W.S., A.W. Roberts, N.A. Nicola, R. Li, and D. Metcalf. 1996. Deficiencies in progenitor cells of multiple hematopoietic lineages and defective megakaryocytopoiesis in mice lacking the thrombopoietic receptor c-Mpl. Blood. 87:2162-2170.

Aster, R.H., and J.H. Jandl. 1964. Platelet sequestration in man. I. Methods. J. Clin. Invest. 43:843-855. http://dx.doi.org/10.1172/JCI104970

Ballem, P.J., G.M. Segal, J.R. Stratton, T. Gernsheimer, J.W. Adamson, and S.J. Slichter. 1987. Mechanisms of thrombocytopenia in chronic autoimmune 
thrombocytopenic purpura. Evidence of both impaired platelet production and increased platelet clearance. J. Clin. Invest. 80:33-40. http:// dx.doi.org/10.1172/JCI113060

Bassik, M.C., L. Scorrano, S.A. Oakes, T. Pozzan, and S.J. Korsmeyer. 2004. Phosphorylation of BCL-2 regulates ER Ca2+ homeostasis and apoptosis. EMBO J. 23:1207-1216. http://dx.doi.org/10.1038/ sj.emboj. 7600104

Boldin, M.P., T.M. Goncharov,Y.V. Goltsev, and D. Wallach. 1996. Involvement of MACH, a novel MORT1/FADD-interacting protease, in Fas/ APO-1- and TNF receptor-induced cell death. Cell. 85:803-815. http://dx.doi.org/10.1016/S0092-8674(00)81265-9

Bouillet, P., D. Metcalf, D.C. Huang, D.M. Tarlinton, T.W. Kay, F. Köntgen, J.M. Adams, and A. Strasser. 1999. Proapoptotic Bcl-2 relative Bim required for certain apoptotic responses, leukocyte homeostasis, and to preclude autoimmunity. Science. 286:1735-1738. http://dx.doi .org/10.1126/science.286.5445.1735

Bruey, J.M., N. Bruey-Sedano, F. Luciano, D. Zhai, R. Balpai, C. Xu, C.L. Kress, B. Bailly-Maitre, X. Li, A. Osterman, et al. 2007. Bcl-2 and $\mathrm{Bcl}-\mathrm{XL}$ regulate proinflammatory caspase-1 activation by interaction with NALP1. Cell. 129:45-56. http://dx.doi.org/10.1016/ j.cell.2007.01.045

Budd, G.T., R. Ganapathi, L.Wood,J. Snyder, D. McLain, and R.M. Bukowski. 1999. Approaches to managing carboplatin-induced thrombocytopenia: focus on the role of amifostine. Semin. Oncol. 26(2, Suppl 7):41-50.

Caserta, T.M., A.N. Smith, A.D. Gultice, M.A. Reedy, and T.L. Brown. 2003. Q-VD-OPh, a broad spectrum caspase inhibitor with potent antiapoptotic properties. Apoptosis. 8:345-352. http://dx.doi.org/10.1023/ A:1024116916932

Chang, M., P.A. Nakagawa, S.A. Williams, M.R. Schwartz, K.L. Imfeld, J.S. Buzby, and D.J. Nugent. 2003. Immune thrombocytopenic purpura (ITP) plasma and purified ITP monoclonal autoantibodies inhibit megakaryocytopoiesis in vitro. Blood. 102:887-895. http://dx.doi.org/10.1182/ blood-2002-05-1475

Chauvier, D., S. Ankri, C. Charriaut-Marlangue, R. Casimir, and E. Jacotot. 2007. Broad-spectrum caspase inhibitors: from myth to reality? Cell Death Differ. 14:387-391. http://dx.doi.org/10.1038/sj.cdd.4402044

Cheng, E.H., M.C. Wei, S. Weiler, R.A. Flavell, T.W. Mak, T. Lindsten, and S.J. Korsmeyer. 2001. BCL-2, BCL-X( ${ }_{\mathrm{L}}$ ) sequester BH3 domainonly molecules preventing $\mathrm{BAX}$ - and $\mathrm{BAK}$-mediated mitochondrial apoptosis. Mol. Cell. 8:705-711. http://dx.doi.org/10.1016/ S1097-2765(01)00320-3

Chernick, M.R. 1999. Bootstrap Methods: A Pratcitioner's Guide (Wiley Series in Probablilty and Statistics). Wiley-Interscience.

Cimprich, K.A., and D. Cortez. 2008. ATR: an essential regulator of genome integrity. Nat. Rev. Mol.Cell Biol. 9:616-627.http://dx.doi.org/10.1038/ nrm 2450

Clarke, M.C., J. Savill, D.B. Jones, B.S. Noble, and S.B. Brown. 2003 Compartmentalized megakaryocyte death generates functional platelets committed to caspase-independent death. J. Cell Biol. 160:577-587. http://dx.doi.org/10.1083/jcb.200210111

De Botton, S., S. Sabri, E. Daugas, Y. Zermati, J.E. Guidotti, O. Hermine, G. Kroemer,W.Vainchenker, and N. Debili. 2002. Platelet formation is the consequence of caspase activation within megakaryocytes. Blood. 100:1310-1317. http://dx.doi.org/10.1182/blood-2002-03-0686

Dolle, R.E., D. Hoyer, C.V. Prasad, S.J. Schmidt, C.T. Helaszek, R.E. Miller, and M.A. Ator. 1994. P1 aspartate-based peptide alpha-((2,6dichlorobenzoyl)oxy)methyl ketones as potent time-dependent inhibitors of interleukin-1 beta-converting enzyme. J. Med. Chem. 37:563-564. http://dx.doi.org/10.1021/jm00031a003

Dowling, M.R., E.C. Josefsson, K.J. Henley, P.D. Hodgkin, and B.T. Kile 2010. Platelet senescence is regulated by an internal timer, not damage inflicted by hits. Blood. 116:1776-1778. http://dx.doi.org/10.1182/ blood-2009-12-259663

Drachman, J.G., D.F. Sabath, N.E. Fox, and K. Kaushansky. 1997. Thrombopoietin signal transduction in purified murine megakaryocytes. Blood. 89:483-492.

Fadeel, B., and S. Orrenius. 2005. Apoptosis: a basic biological phenomenon with wide-ranging implications in human disease. J. Intern. Med. 258:479-517. http://dx.doi.org/10.1111/j.1365-2796.2005.01570.x
Fernandes-Alnemri, T., R.C. Armstrong, J. Krebs, S.M. Srinivasula, L. Wang, F. Bullrich, L.C. Fritz, J.A. Trapani, K.J. Tomaselli, G. Litwack, and E.S. Alnemri. 1996. In vitro activation of CPP32 and Mch3 by Mch4, a novel human apoptotic cysteine protease containing two FADD-like domains. Proc. Natl. Acad. Sci. USA. 93:7464-7469. http://dx.doi.org/10.1073/ pnas.93.15.7464

Galluzzi, L., N. Joza, E. Tasdemir, M.C. Maiuri, M. Hengartner, J.M. Abrams, N.Tavernarakis, J. Penninger, F. Madeo, and G. Kroemer. 2008. No death without life: vital functions of apoptotic effectors. Cell Death Differ. 15:1113-1123. http://dx.doi.org/10.1038/cdd.2008.28

Green, D.R., and G. Kroemer. 2004. The pathophysiology of mitochondrial cell death. Science. 305:626-629. http://dx.doi.org/10.1126/ science. 1099320

Heilmann, E., P. Friese, S. Anderson, J.N. George, S.R. Hanson, S.A. Burstein, and G.L. Dale. 1993. Biotinylated platelets: a new approach to the measurement of platelet life span. Br. J. Haematol. 85:729-735. http://dx.doi .org/10.1111/j.1365-2141.1993.tb03216.x

Hitchcock, I.S., N.E. Fox, N. Prévost, K. Sear, S.J. Shattil, and K. Kaushansky. 2008. Roles of focal adhesion kinase (FAK) in megakaryopoiesis and platelet function: studies using a megakaryocyte lineage specific FAK knockout. Blood. 111:596-604. http://dx.doi.org/10.1182/blood2007-05-089680

Houwerzijl, E.J., N.R. Blom, J.J. van der Want, M.T.Esselink, J.J. Koornstra, J.W.Smit, H. Louwes, E.Vellenga, and J.T. de Wolf. 2004. Ultrastructural study shows morphologic features of apoptosis and para-apoptosis in megakaryocytes from patients with idiopathic thrombocytopenic purpura. Blood. 103:500-506. http://dx.doi.org/10.1182/ blood-2003-01-0275

Italiano, J.E. Jr., P. Lecine, R.A. Shivdasani, and J.H. Hartwig. 1999. Blood platelets are assembled principally at the ends of proplatelet processes produced by differentiated megakaryocytes. J. Cell Biol. 147:1299-1312. http://dx.doi.org/10.1083/jcb.147.6.1299

Josefsson, E.C., H.H. Gebhard, T.P. Stossel, J.H. Hartwig, and K.M. Hoffmeister. 2005. The macrophage alphaMbeta2 integrin alphaM lectin domain mediates the phagocytosis of chilled platelets. J. Biol. Chem. 280:18025-18032. http://dx.doi.org/10.1074/jbc.M501178200

Junt, T., H. Schulze, Z. Chen, S. Massberg,T. Goerge, A. Krueger, D.D. Wagner, T. Graf, J.E. Italiano Jr., R.A. Shivdasani, and U.H. von Andrian. 2007. Dynamic visualization of thrombopoiesis within bone marrow. Science. 317:1767-1770. http://dx.doi.org/10.1126/science.1146304

Kaluzhny, Y., and K. Ravid. 2004. Role of apoptotic processes in platelet biogenesis. Acta Haematol. 111:67-77. http://dx.doi.org/10.1159/ 000074487

Kaluzhny, Y., G. Yu, S. Sun, P.A. Toselli, B. Nieswandt, C.W. Jackson, and K. Ravid. 2002. BclxL overexpression in megakaryocytes leads to impaired platelet fragmentation. Blood. 100:1670-1678. http://dx.doi .org/10.1182/blood-2001-12-0263

Kirsch,D.G., P.M. Santiago, E. diTomaso,J.M.Sullivan,W.S. Hou,T.Dayton, L.B. Jeffords, P. Sodha, K.L. Mercer, R. Cohen, et al. 2010. p53 controls radiation-induced gastrointestinal syndrome in mice independent of apoptosis. Science. 327:593-596. http://dx.doi.org/10.1126/ science. 1166202

Knudson, C.M., K.S. Tung, W.G. Tourtellotte, G.A. Brown, and S.J. Korsmeyer. 1995. Bax-deficient mice with lymphoid hyperplasia and male germ cell death. Science. 270:96-99. http://dx.doi.org/10.1126/ science.270.5233.96

Kodama, T., T. Takehara, H. Hikita, S. Shimizu, M. Shigekawa, W. Li, T. Miyagi, A. Hosui, T.Tatsumi, H. Ishida, et al. 2011. BH3-only activator proteins Bid and Bim are dispensable for Bak/Bax-dependent thrombocyte apoptosis induced by $\mathrm{Bcl}-\mathrm{xL}$ deficiency:molecular requisites for the mitochondrial pathway to apoptosis in platelets. J. Biol. Chem. 286: 13905-13913. http://dx.doi.org/10.1074/jbc.M110.195370

Kozuma,Y., H. Kojima, S. Yuki, H. Suzuki, and T. Nagasawa. 2007. Continuous expression of $\mathrm{Bcl}-\mathrm{xL}$ protein during megakaryopoiesis is posttranslationally regulated by thrombopoietin-mediated Akt activation, which prevents the cleavage of Bcl-xL.J.Thromb. Haemost. 5:1274-1282. http://dx.doi.org/10.1111/j.1538-7836.2007.02546.x

Kozuma,Y., S.Yuki,H. Ninomiya,T. Nagasawa, and H. Kojima. 2009. Caspase activation is involved in early megakaryocyte differentiation but not 
in platelet production from megakaryocytes. Leukemia. 23:1080-1086. http://dx.doi.org/10.1038/leu.2009.7

Krajewski, S., M. Krajewska, A. Shabaik, H.G. Wang, S. Irie, L. Fong, and J.C. Reed. 1994. Immunohistochemical analysis of in vivo patterns of Bcl-X expression. Cancer Res. 54:5501-5507.

Kroemer, G., L. Galluzzi, P. Vandenabeele, J. Abrams, E.S. Alnemri, E.H Baehrecke, M.V. Blagosklonny, W.S. El-Deiry, P. Golstein, D.R. Green, et al; Nomenclature Committee on Cell Death 2009. 2009. Classification of cell death: recommendations of the Nomenclature Committee on Cell Death 2009. Cell Death Differ. 16:3-11. http://dx.doi.org/10.1038/ cdd. 2008.150

Kruse, E.A., S.J. Loughran, T.M. Baldwin, E.C. Josefsson, S. Ellis, D.K Watson, P. Nurden, D. Metcalf, D.J. Hilton, W.S. Alexander, and B.T. Kile.2009.Dual requirement for the ETS transcription factors Fli-1 and Erg in hematopoietic stem cells and the megakaryocyte lineage. Proc. Natl. Acad. Sci. USA. 106:13814-13819. http://dx.doi.org/10.1073/ pnas. 0906556106

Leber, B., F. Geng, J. Kale, and D.W. Andrews. 2010. Drugs targeting Bcl-2 family members as an emerging strategy in cancer. Expert Rev. Mol. Med. 12:e28. http://dx.doi.org/10.1017/S1462399410001572

Lecine, P., J.L.Villeval, P.Vyas, B. Swencki, Y. Xu, and R.A. Shivdasani. 1998. Mice lacking transcription factor NF-E2 provide in vivo validation of the proplatelet model of thrombocytopoiesis and show a platelet production defect that is intrinsic to megakaryocytes. Blood. 92:1608-1616.

Levin, J., J.P. Peng, G.R. Baker, J.L.Villeval, P. Lecine, S.A. Burstein, and R.A. Shivdasani. 1999. Pathophysiology of thrombocytopenia and anemia in mice lacking transcription factor NF-E2. Blood. 94:3037-3047.

Lindsten, T., A.J. Ross, A. King, W.X. Zong, J.C. Rathmell, H.A. Shiels, E. Ulrich, K.G. Waymire, P. Mahar, K. Frauwirth, et al. 2000. The combined functions of proapoptotic Bcl-2 family members bak and bax are essential for normal development of multiple tissues. Mol. Cell. 6:1389-1399. http://dx.doi.org/10.1016/S1097-2765(00)00136-2

Mason, K.D., M.R. Carpinelli, J.I. Fletcher, J.E. Collinge, A.A. Hilton, S. Ellis, P.N. Kelly, P.G. Ekert, D. Metcalf, A.W. Roberts, et al. 2007. Programmed anuclear cell death delimits platelet life span. Cell. 128:1173-1186. http://dx.doi.org/10.1016/j.cell.2007.01.037

Matic, G.B., E.S. Chapman, M. Zaiss, G. Rothe, and G. Schmitz. 1998. Whole blood analysis of reticulated platelets: improvements of detection and assay stability. Cytometry. 34:229-234.

McMillan, R., and D. Nugent. 2005. The effect of antiplatelet autoantibodies on megakaryocytopoiesis. Int.J. Hematol. 81:94-99. http://dx.doi .org/10.1532/IJH97.04168

Motoyama, N., F.P. Wang, K.A. Roth, H. Sawa, K. Nakayama, K. Nakayama, I. Negishi, S. Senju, Q.Zhang, S. Fujii, and D.Y.Loh. 1995. Massive cell death of immature hematopoietic cells and neurons in Bcl-x-deficient mice. Science. 267:1506-1510. http://dx.doi.org/10.1126/science.7878471

Motoyama, N., T. Kimura, T. Takahashi, T. Watanabe, and T. Nakano. 1999. bcl-x prevents apoptotic cell death of both primitive and definitive erythrocytes at the end of maturation. J. Exp. Med. 189:1691-1698. http://dx.doi.org/10.1084/jem.189.11.1691

Muzio, M., A.M. Chinnaiyan, F.C. Kischkel, K. O’Rourke, A. Shevchenko, J. Ni, C. Scaffidi, J.D. Bretz, M. Zhang, R. Gentz, et al. 1996. FLICE, a novel FADD-homologous ICE/CED-3-like protease, is recruited to the CD95 (Fas/APO-1) death-inducing signaling complex. Cell. 85:817827. http://dx.doi.org/10.1016/S0092-8674(00)81266-0

Norol, F., N.Vitrat, E. Cramer, J. Guichard, S.A. Burstein, W.Vainchenker, and N. Debili. 1998. Effects of cytokines on platelet production from blood and marrow CD34+ cells. Blood. 91:830-843.

Ogilvy, S., D. Metcalf, C.G. Print, M.L. Bath, A.W. Harris, and J.M. Adams. 1999 Constitutive Bcl-2 expression throughout the hematopoietic compartment affects multiple lineages and enhances progenitor cell survival. Proc. Natl.Acad. Sci. USA. 96:14943-14948. http://dx.doi.org/10.1073/pnas.96.26.14943

Oltersdorf, T., S.W. Elmore, A.R. Shoemaker, R.C. Armstrong, D.J. Augeri, B.A. Belli, M. Bruncko, T.L. Deckwerth, J. Dinges, P.J. Hajduk, et al. 2005. An inhibitor of Bcl-2 family proteins induces regression of solid tumours. Nature. 435:677-681. http://dx.doi.org/10.1038/nature03579

Patel, S.R., J.H. Hartwig, and J.E. Italiano Jr. 2005. The biogenesis of platelets from megakaryocyte proplatelets. J. Clin. Invest. 115:3348-3354. http:// dx.doi.org/10.1172/JCI26891
Pattingre, S., A.Tassa, X. Qu, R. Garuti, X.H. Liang, N. Mizushima, M. Packer, M.D. Schneider, and B. Levine. 2005. Bcl-2 antiapoptotic proteins inhibit Beclin 1-dependent autophagy. Cell. 122:927-939. http://dx.doi .org/10.1016/j.cell.2005.07.002

Petros, A.M., J.R. Huth, T. Oost, C.-M. Park, H. Ding, X. Wang, H. Zhang, P. Nimmer, R. Mendoza, C. Sun, et al. 2010. Discovery of a potent and selective Bcl-2 inhibitor using SAR by NMR. Bioorg. Med. Chem. Lett. 20:6587-6591. http://dx.doi.org/10.1016/j.bmcl.2010.09.033

Pleines, I., A. Eckly, M. Elvers, I. Hagedorn, S. Eliautou, M. Bender, X. Wu, F. Lanza, C. Gachet, C. Brakebusch, and B. Nieswandt. 2010. Multiple alterations of platelet functions dominated by increased secretion in mice lacking Cdc42 in platelets. Blood. 115:3364-3373. http://dx.doi .org/10.1182/blood-2009-09-242271

Rathmell, J.C., T. Lindsten, W.-X. Zong, R.M. Cinalli, and C.B. Thompson. 2002. Deficiency in Bak and Bax perturbs thymic selection and lymphoid homeostasis. Nat. Immunol. 3:932-939. http://dx.doi.org/10 $.1038 /$ ni834

Ren, D., H.C. Tu, H. Kim, G.X. Wang, G.R. Bean, O. Takeuchi, J.R. Jeffers, G.P. Zambetti, J.J. Hsieh, and E.H. Cheng. 2010. BID, BIM, and PUMA are essential for activation of the BAX- and BAKdependent cell death program. Science. 330:1390-1393. http://dx.doi .org/10.1126/science.1190217

Roberts, A.W., J.F. Seymour, J.R. Brown, W. Wierda, T.J. Kipps, S.L. Khaw, D.A. Carney, S.Z. He, D.C.S. Huang, H. Xiong, et al. Substantial susceptibility of chronic lymphocytic leukemia to BCL2 inhibition.: results of phase 1 study of navitoclax (ABT-263) in patients with relapsed refractory disease. J. Clin. Oncol. In Press.

Rucker, E.B. III, P. Dierisseau, K.U. Wagner, L. Garrett, A. WynshawBoris, J.A. Flaws, and L. Hennighausen. 2000. Bcl-x and Bax regulate mouse primordial germ cell survival and apoptosis during embryogenesis. Mol. Endocrinol. 14:1038-1052. http://dx.doi.org/10.1210/ me.14.7.1038

Sanz, C., I. Benet, C. Richard, B. Badia, E.J. Andreu, F. Prosper, and J.L. Fernández-Luna. 2001. Antiapoptotic protein $\mathrm{Bcl}-\mathrm{x}(\mathrm{L})$ is up-regulated during megakaryocytic differentiation of $\mathrm{CD} 34(+)$ progenitors but is absent from senescent megakaryocytes. Exp. Hematol. 29:728-735. http://dx.doi.org/10.1016/S0301-472X(01)00635-X

Schaefer, B.C., M.L. Schaefer, J.W. Kappler, P. Marrack, and R.M. Kedl. 2001. Observation of antigen-dependent CD8+ T-cell/ dendritic cell interactions in vivo. Cell. Immunol. 214:110-122. http://dx.doi .org/10.1006/cimm.2001.1895

Schoenwaelder, S.M., Y. Yuan, E.C. Josefsson, M.J. White, Y. Yao, K.D. Mason, L.A. O'Reilly, K.J. Henley, A. Ono, S. Hsiao, et al. 2009. Two distinct pathways regulate platelet phosphatidylserine exposure and procoagulant function. Blood. 114:663-666. http://dx.doi .org/10.1182/blood-2009-01-200345

Shivdasani, R.A., M.F. Rosenblatt, D. Zucker-Franklin, C. W. Jackson, P. Hunt, C.J. Saris, and S.H. Orkin. 1995. Transcription factor NF-E2 is required for platelet formation independent of the actions of thrombopoietin/ MGDF in megakaryocyte development. Cell. 81:695-704. http://dx.doi .org/10.1016/0092-8674(95)90531-6

Siegel, R.M. 2006. Caspases at the crossroads of immune-cell life and death. Nat. Rev. Immunol. 6:308-317. http://dx.doi.org/10.1038/nri1809

Solary, E., F. Giordanetto, and G. Kroemer. 2008. Re-examining the role of cytochrome c in cell death. Nat. Genet. 40:379-380. http://dx.doi .org/10.1038/ng0408-379

Takeuchi, O., J. Fisher, H. Suh, H. Harada, B.A. Malynn, and S.J. Korsmeyer. 2005. Essential role of BAX,BAK in B cell homeostasis and prevention of autoimmune disease. Proc. Natl. Acad. Sci. USA. 102:11272-11277. http://dx.doi.org/10.1073/pnas.0504783102

Temkin, V., Q. Huang, H. Liu, H. Osada, and R.M. Pope. 2006. Inhibition of ADP/ATP exchange in receptor-interacting protein-mediated necrosis. Mol. Cell. Biol. 26:2215-2225. http://dx.doi.org/10.1128/MCB.26 .6.2215-2225.2006

Terui, Y., Y. Furukawa, J. Kikuchi, S. Iwase, K. Hatake, and Y. Miura. 1998. $\mathrm{Bcl}-\mathrm{x}$ is a regulatory factor of apoptosis and differentiation in megakaryocytic lineage cells. Exp. Hematol. 26:236-244.

Tiedt, R., T. Schomber, H. Hao-Shen, and R.C. Skoda. 2007. Pf4-Cre transgenic mice allow the generation of lineage-restricted gene knockouts for 
studying megakaryocyte and platelet function in vivo. Blood. 109:15031506. http://dx.doi.org/10.1182/blood-2006-04-020362

Vadhan-Raj, S. 2009. Management of chemotherapy-induced thrombocytopenia: current status of thrombopoietic agents. Semin. Hematol. 46:S26S32. http://dx.doi.org/10.1053/j.seminhematol.2008.12.007

Vairo, G., K.M. Innes, and J.M. Adams. 1996. Bcl-2 has a cell cycle inhibitory function separable from its enhancement of cell survival. Oncogene. 13:1511-1519.

Wei, M.C., W.X. Zong, E.H. Cheng, T. Lindsten, V. Panoutsakopoulou, A.J. Ross, K.A. Roth, G.R. MacGregor, C.B.Thompson, and S.J. Korsmeyer. 2001. Proapoptotic BAX and BAK: a requisite gateway to mitochondrial dysfunction and death. Science. 292:727-730. http://dx.doi .org/10.1126/science. 1059108

Willis, S.N., J.I. Fletcher,T. Kaufmann, M.F. van Delft, L. Chen, P.E. Czabotar, H. Ierino, E.F. Lee, W.D. Fairlie, P. Bouillet, et al. 2007. Apoptosis initiated when BH3 ligands engage multiple Bcl-2 homologs, not Bax or Bak. Science. 315:856-859. http://dx.doi.org/10.1126/science.1133289

Wilson, W.H., O.A. O'Connor, M.S. Czuczman, A.S. LaCasce, J.F. Gerecitano, J.P. Leonard, A. Tulpule, K. Dunleavy, H. Xiong, Y.L. Chiu, et al. 2010 Navitoclax, a targeted high-affinity inhibitor of BCL-2, in lymphoid malignancies: a phase 1 dose-escalation study of safety, pharmacokinetics, pharmacodynamics, and antitumour activity. Lancet Oncol. 11:1149-1159. http://dx.doi.org/10.1016/S1470-2045(10)70261-8
Wozniak,A.J., and W.E. Ross. 1983. DNA damage as a basis for 4'-demethylepipodophyllotoxin-9-(4,6-O-ethylidene-beta-D-glucopyranoside) (etoposide) cytotoxicity. Cancer Res. 43:120-124.

Wu,Y.T., H.L.Tan, Q. Huang, X.J. Sun, X. Zhu, and H.M. Shen. 2011.zVADinduced necroptosis in L929 cells depends on autocrine production of TNF $\alpha$ mediated by the PKC-MAPKs-AP-1 pathway. Cell Death Differ. 18:26-37. http://dx.doi.org/10.1038/cdd.2010.72

Youle, R.J., and A. Strasser. 2008. The BCL-2 protein family: opposing activities that mediate cell death. Nat. Rev. Mol. Cell Biol. 9:47-59. http://dx.doi.org/10.1038/nrm2308

Zauli, G., L. Catani, D. Gibellini, M.C. Re, N. Vianelli, V. Colangeli, C. Celeghini, S. Capitani, and M. La Placa. 1996. Impaired survival of bone marrow GPIIb/IIa+ megakaryocytic cells as an additional pathogenetic mechanism of HIV-1-related thrombocytopenia. Br.J. Haematol. 92:711717. http://dx.doi.org/10.1046/j.1365-2141.1996.367904.x

Zeuner, A., M. Signore, D. Martinetti, M. Bartucci, C. Peschle, and R. De Maria. 2007. Chemotherapy-induced thrombocytopenia derives from the selective death of megakaryocyte progenitors and can be rescued by stem cell factor. Cancer Res. 67:4767-4773. http://dx.doi.org/10.1158/00085472. CAN-06-4303

Zucker-Franklin, D., C.S. Termin, and M.C. Cooper. 1989. Structural changes in the megakaryocytes of patients infected with the human immune deficiency virus (HIV-1). Am. J. Pathol. 134:1295-1303. 


\section{University Library}

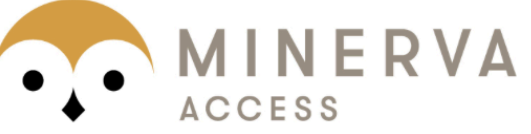

A gateway to Melbourne's research publications

Minerva Access is the Institutional Repository of The University of Melbourne

\section{Author/s:}

Josefsson, EC;James, C;Henley, KJ;Debrincat, MA;Rogers, KL;Dowling, MR;White, MJ;Kruse, EA;Lane, RM;Ellis, S;Nurden, P;Mason, KD;O'Reilly, LA;Roberts, AW;Metcalf, D;Huang, DCS;Kile, BT

Title:

Megakaryocytes possess a functional intrinsic apoptosis pathway that must be restrained to survive and produce platelets

\section{Date:}

2011-09-26

\section{Citation:}

Josefsson, E. C., James, C., Henley, K. J., Debrincat, M. A., Rogers, K. L., Dowling, M. R., White, M. J., Kruse, E. A., Lane, R. M., Ellis, S., Nurden, P., Mason, K. D., O'Reilly, L. A., Roberts, A. W., Metcalf, D., Huang, D. C. S. \& Kile, B. T. (2011). Megakaryocytes possess a functional intrinsic apoptosis pathway that must be restrained to survive and produce platelets. JOURNAL OF EXPERIMENTAL MEDICINE, 208 (10), pp.2017-2031. https:// doi.org/10.1084/jem.20110750.

Persistent Link:

http://hdl.handle.net/11343/264046

License:

CC BY-NC-SA 